\title{
NATURAL RESOURCE ABUNDANCE AND ECONOMIC GROWTH
}

\author{
Jeffrey D. Sachs
}

Andrew M. Warner

Working Paper 5398

\section{NATIONAL BUREAU OF ECONOMIC RESEARCH 1050 Massachusetts Avenue \\ Cambridge, MA 02138 \\ December 1995}

This is a substantially revised version of our earlier paper, "Natural Resources and Economic Growth," Harvard Institute for International Development, January 1995. We wish to thank Alan Taylor and participants in the HIID research retreat for helpful comments, Robert Barro, JongWha Lee, Brad DeLong, Lawrence Summers, Robert King and Ross Levine for kindly sharing an extensive amount of data with us from their previous work. We would also like to thank Jeff Kerzner and Jennifer Harris for helping with the data. This paper is part of NBER's research programs in Growth, and International Finance and Macroeconomics. Any opinions expressed are those of the authors and not those of the National Bureau of Economic Research.

(C) 1995 by Jeffrey D. Sachs and Andrew M. Warner. All rights reserved. Short sections of text, not to exceed two paragraphs, may be quoted without explicit permission provided that full credit, including $(\mathcal{O}$ notice, is given to the source. 


\title{
NATURAL RESOURCE ABUNDANCE AND ECONOMIC GROWTH
}

\begin{abstract}
One of the surprising features of modern economic growth is that economies with abundant natural resources have tended to grow less rapidly than natural-resource-scarce economies. In this paper we show that economies with a high ratio of natural resource exports to GDP in 1971 (the base year) tended to have low growth rates during the subsequent period 1971-89. This negative relationship holds true even after controlling for variables found to be important for economic growth, such as initial per capita income, trade policy, government efficiency, investment rates, and other variables. We explore the possible pathways for this negative relationship by studying the cross-country effects of resource endowments on trade policy, bureaucratic efficiency, and other determinants of growth. We also provide a simple theoretical model of endogenous growth that might help to explain the observed negative relationship.
\end{abstract}

Jeffrey D. Sachs

Harvard Institute for

International Development

One Eliot Street

Cambridge, MA 02138

and NBER
Andrew M. Warner

Harvard Institute for

International Development

One Eliot Street

Cambridge, MA 02138 


\section{Natural Resource Abundance and Economic Growth ${ }^{1}$}

\section{Section 1. Introduction.}

One of the surprising features of economic life is that resource-poor economies often vastly outperform resource-rich economies in economic growth. The basic pattern is evident in a sample of 97 developing countries in Figure 1, where we graph each country's annual growth rate between 1970-89 in relation to the country's natural resource-based exports in 1970, measured as a percent of GDP.

Resource-based exports are defined as agriculture, minerals, and fuels. On average, countries with a high value of resource-based exports to GDP tend to have a lower growth rate. Later in the paper we will show that this basic negative relationship is present after controlling for other relevant characteristics of the economies, such as initial income levels and trade policies.

The oddity of resource-poor economies outperforming resource-rich economies has been a constant motif of economic history. In the seventeenth century, resource-poor Netherlands eclipsed Spain, despite the overflow of gold and silver from the Spanish colonies in the New World. In the nineteenth and twentieth centuries, resource-poor countries such as Switzerland and Japan surged ahead of resource-abundant economies such as Russia. In the past thirty years, the world's star performers have been the resource-poor Newly Industrializing Economies (NIEs) of East Asia - Korea, Taiwan, Hong Kong, Singapore - while many resource-rich economies such as the oil-rich countries of Mexico, Nigeria, Venezuela, have gone bankrupt.

The negative association between resource abundance and growth certainly poses a conceptual

puzzle. After all, natural resources raise the wealth and the purchasing power over imports, so that

\footnotetext{
'This is a substantially revised version of our earlier paper, "Natural Resources and Economic Growth," Harvard Institute for International Development, January 1995. We wish to thank Alan Taylor and participants in the HIID research retreat for helpful comments, Robert Barro, Jong-Wha Lee, Brad DeLong, Lawrence Summers, Robert King and Ross Levine for kindly sharing an extensive amount of data with us from their previous work. We would also like to thank Jeff Kerzner and Jennifer Harris for helping with the data.
} 
resource abundance might be expected to raise an economy's investment and growth rates as well. Many oil-rich countries have aimed to use their vast oil revenues to finance diversified investments and a "big push" in industrial development. Venezuelans called this "sowing the seeds of oil revenues." Moreover, as pointed out recently by Williamson and DeLong (1994), when a natural resource has high transport costs, then its physical availability within the economy may be essential for the introduction of a new industry or a new technology. As a key historical example, coal and iron ore deposits were the sine qua non for the development of an indigenous steel industry in the late nineteenth century. In that case, resource-rich economies such as Britain, Germany, and the U.S., experienced particularly rapid industrial development at the end of the last century. With falling transport costs, however, the physical availability of resources within the national economy is rarely as decisive today as it was a century ago. Thus, Japan and Korea have succeeded in become world-class steel producers despite their virtual complete dependence on imports of iron ore. Even if natural resources are no longer a decisive advantage to economic growth, it is surely surprising that they might pose an actual disadvantage. Is there a curse to easy riches?

Many previous researchers have noted the failure of resource-led growth in the 1970 s and 1980 s, though to the best of our knowledge, none has confirmed the adverse effects of resource abundance on growth on the basis of a worldwide, comparative study of growth, as we do in this paper. Important earlier findings of the failures of resource-led development include several outstanding works by Alan Gelb, culminating in Gelb (1988), and several key studies by Auty, most comprehensively in Auty (1990). These studies suggest many of the economic and political factors that may have played a role in the disappointing performance of resource-abundant economies, and so provide a basis for some of the hypotheses tested later in the paper on the cross-country data. A recent and fascinating paper by Berge et. al. (1994) is similar in motivation and spirit to this paper, and also points to the adverse role of natural resource endowments (measured mainly by land and population density) on growth and manufacturing exports.

There are indeed a large number of hypotheses that can be raised (in addition to the hypothesis, 
later discarded, that the negative relationship in Figure 1 is purely spurious). One early explanation of the phenomenon is social: that easy riches lead to sloth. The sixteenth century French political philosopher Jean Bodin (1576, reprinted 1962) asserted as much when he claimed that:

men of a fat and fertile soil, are most commonly effeminate and cowards; whereas contrariwise a barren country make men temperate by necessity, and by consequence careful, vigilant, and industrious. $(V, 1,565)^{2}$

An alternative approach lies in the area of political economy. Lane and Tornell (1995) have recently argued in a formal model that resource-rich economies are subject to more extreme rent-seeking behavior than resource-poor economies, as national politics is oriented to grabbing the rents earned by the natural resource endowments. In their model, a windfall coming from a terms-of-trade improvement or a discovery of natural resource deposits can lead to a "feeding frenzy" in which competing factions fight for the natural resource rents, and end up inefficiently exhausting the public good. The case studies in Gelb (1988) and Auty (1990) lend much support to these political channels of influence.

Another set of possibilities is strictly economic, drawing upon the ideas widespread in the development literature in the 1940 s and $50 \mathrm{~s}$, and in the Dutch Disease models more recently. One important tradition in the development literature, associated with Raul Prebish and Hans Singer, argued that resource-based growth would be ineffective because the world prices of primary exports relative to manufactures show a deep tendency towards secular decline. Closely related views held that world demand for manufacturers would grow faster than demand for primary products or that the rich countries would be more protectionist against primary imports than manufacturing imports.

According to the "Prebisch hypothesis," later promoted by the United Nations Economic Commissions in Latin America, Africa, and Asia, the practical policy implication was that developing countries should shun their dependency on natural resource exports, through state-led industrialization. The great historical mistake of this thinking, however, was to recommend industrialization through

${ }^{2} 0$. Cited in Stephen Holmes, Passions and Constraints, Chicago: University of Chicago Press, 1995, p. 109, from Jean Bodin, The Six Books of a Commonwealth [Les six livres de la republique], trans. Robert Knolles, ed. K. D. McRae (Cambridge: Harvard University Press, 1962). 
prolonged import-substitution behind tariff and quota barriers, rather than through export promotion. State-led industrialization foundered almost everywhere that it was attempted (see Sachs and Warner 1995 for a recent cross-country analysis of the adverse effects of protectionism on long-term growth).

A second set of economic arguments against natural-resource-based growth involved the purported characteristics of the domestic economy rather than the international economy. The work of Hirschman (1958), Seers (1964), and Baldwin (1966) encouraged the view that beneficial "forward and backward linkages" from primary exports to the rest of the economy would be small. The basic idea was that manufacturing, as opposed to natural-resource production, leads to a more complex division of labor and hence to a higher standard of living. The negative assessment of resource-based development in due course led to a revisionist literature describing successful cases of staples-led growth. See for example Roemer (1970) on Peru, and further success cases reviewed in Lewis (1989).

Recently, Sweder van Wijnbergen (1984) and Kiminori Matsuyama (1992) have provided formal models of the "linkages approach." This study follows Matsuyama's framework. Matsuyama examines the role of agriculture in economic development in a model in which manufacturing is characterized by learning-by-doing. In Matsuyama's model there are two sectors, agriculture and manufacturing. Manufacturing is characterized by learning-by-doing that is external to the enterprise but internal to the manufacturing sector as a whole. In other words, learning is proportional to total sectoral production, not to the production of an individual firm. Forces which push the economy away from manufacturing and towards agriculture lower the growth rate of the economy, by reducing the learning-induced growth of manufacturing. The market equilibrium is not efficient because the learning effects are external to the firm. In this context, Matsuyama shows that trade liberalization in a land-intensive economy could actually slow economic growth by inducing the economy to shift resources away from manufacturing and towards agriculture.

In Matsuyama's model, the adverse effects of agricultural production arise because the agricultural sector directly employees the factors of production that otherwise would be in manufacturing. Such a framework may be useful for studying labor-intensive production of natural resources, such as in 
agriculture, but it is less relevant for a natural resource sector like oil production, which use very little labor, and therefore does not directly draw employment from manufacturing. Fortunately, it is easy to extend Matsuyama's same point in a more realistic and general setting, using the framework of the Dutch disease model. We present this extension in Appendix A.

In the Dutch disease model, the economy has three sectors: a tradeable natural resource sector, a tradeable (non-resource) manufacturing sector, and a non-traded sector. The greater the natural resource endowment, the higher is the demand for non-tradeable goods, and consequently, the smaller will be the allocation of labor and capital to the manufacturing sector. Therefore, when natural resources are abundant, tradeables production is concentrated in natural resources rather than manufacturing, and capital and labor that otherwise might be employed in manufacturing are pulled into the non-traded goods sector. As a corollary, when an economy experiences a resource boom (either a terms-of-trade improvement, or a resource discovery), the manufacturing sector tends to shrink and the non-traded goods sector tends to expand.

The shrinkage of the manufacturing sector is dubbed the "disease," though there is nothing harmful about the decline in manufacturing if neoclassical, competitive conditions prevail in the economy. The Dutch Disease can be a real disease, however - and a source of chronic slow growth - if there is something special about the sources of growth in manufacturing, such as the "backward and forward linkages" stressed by Hirshman, et. al., or the learning-by-doing stressed by van Wijnbergen and Matsuyama. If manufacturing is characterized by externalities in production, then the shrinkage of the manufacturing sector caused by resource abundance can lead to a socially inefficient decline in growth. The economy loses the benefits of the external economies or IRS to manufacturing. The studies by Gelb (1988) confirm the importance of general Dutch Disease effects of resource booms, i.e. in the squeeze of manufactures in the face of resource booms. Timmer (1982) similarly provides evidence that agriculture is squeezed by an increase of energy exports. The links of these Dutch Disease effects to the loss of production externalities, however, remains speculative and as yet unproven.

The rest of the paper is organized as follows. In Section 2, we examine the cross-country growth 
record during 1970-89. We ask whether the evidence from the past 20 years supports the notion that abundant natural resources depress growth, and find the answer to be "Yes." In Section 3, we present some preliminary results on possible pathways, by studying the effects of natural resource dependence on political and economic variables. Section 4 presents a summary and some thoughts about future research in this area. Appendix A shows the extension of the Matsuyama model to the case of tradeable and nontradeable goods. Appendix B describes the data used in the paper. 


\section{Section 2. Empirical Evidence on Resource-Based Growth}

We begin with cross-country growth equations described in Barro and Sala-I-Martin (1995), and used recently by Sachs and Warner (1995) in a study of the linkages of trade policy and growth. The basic idea is that economic growth in economy I between time $t=0$ and $t=T$ (in this case, 1970 and 1989) should be a negative function of initial income $Y_{0}^{i}$ and a vector of other structural characteristics of the economy Zi:

$(1 / T) \log \left(Y_{T}^{i} Y_{0}^{i}\right)=\delta_{0}+\delta_{1} \log \left(Y^{i}\right)+\delta^{\prime} Z^{i}+\varepsilon^{i}$

Our goal is to test whether measures of resource dependence are among the Z's. Our preferred measure of resource dependence is the ratio of primary-product exports to GDP in 1970, which we denote SXP. We have also tested other possible measures of resource dependence, as we shall mention.

Our empirical starting point is to include just initial income (LGDP70) and the share of primary exports in GDP in 1971 (SXP), as shown in regression 1 in table 1. Holding initial income constant, a higher share of primary exports at the start of the period is associated with lower growth over the next 20 years, with an estimated coefficient of -6.920 , which is highly statistically significant (t-ratio $=-\mathbf{3 . 2 8}$ ). To gauge the size of this coefficient, note that SXP is measured as a share of GDP, with a cross-country mean in 1971 of 0.1282 and a standard deviation of 0.1344 . Therefore, a unit standard deviation increase in the share of primary exports in 1971 would be associated with a reduction in annual per-capita growth of a little less than one percent per year, specifically -0.93 percent per annum $\left(=-6.920^{*} 0.1344\right)$. Later in the paper we will have more to say about the pathways of this effect, but this calculation gives a rough idea of the orders of magnitude of the growth effect associated with resource abundance.

It might be the case that this negative association between resource wealth and growth is spurious, and actually reflects an association between resource wealth and something else that affects growth. For example, some have argued that resource-rich countries are more prone to adopt inwardlooking economic policies, or to develop bloated and ineffective bureaucracies. Alternatively, natural 
resource wealth might foster social polarization and income inequality as the elites use their political positions to expropriate a disproportionate share of the resource wealth. Finally, dependence on a primary resource is often alleged to make the country more vulnerable to external shocks.

In table 1, we look at the evidence for such effects by adding a number of variables to the basic growth regression. These regressions are meant to serve two purposes. The first is to see if these additional variables - some of which are included in other growth studies - are themselves significantly associated with growth once resource wealth is taken into account. The second is to see if the SXP association is sensitive to their inclusion.

In regression 1.2 we add an openness variable, SOPEN, that measures the fraction of years between 1965 and 1989 that the country was integrated with the global economy. A country is said to be integrated if it maintained reasonably low tariffs and quotas, and did not have an excessively high black market exchange rate premium (see Sachs and Warner, 1995 for more details on the formal criteria). A country that is open every year between 1965 and 1989 receives a value SOPEN $=1$. A country that is always closed during these years receives a value SOPEN $=0$. The regression results demonstrate that openness is very strongly and positively associated with growth, as we showed in Sachs and Warner (1995). Importantly, the primary export coefficient is significant even after controlling for trade policy. The value of the coefficient is in fact even higher than in regression 1.

The other variables considered in table 1 are: INV7089, the average investment to GDP ratio over the period 1970-1989; BUR, an index that measures the quality of the bureaucracy in the period 19801983 (from Mauro, 1995) 3 $^{3}$ TTSD, the standard deviation of the log of the external terms-of-trade index over the period 1971-1989 (from World Tables, 1993); and INEQ, the ratio of the income share of the top 20 percent of households to the income share of the bottom 20 percent of households.

The table shows that the share of primary exports in GDP remains significant after controlling for

3 The bureaucracy index is a simple composite of three indexes, to measure: (1) efficiency of the judiciary; (2) lack of red tape; and (3) lack of corruption. These indexes are based on surveys conducted by Business International over the period 1980-83. 
these variables. The table also shows that the last two of these variables, TTSD and INEQ, are not themselves significantly associated with growth, while openness, investment and bureaucratic quality are significantly associated with growth. ${ }^{4}$ Mauro (1995) had earlier demonstrated the significance of the bureaucratic quality measure for cross-country growth.

In equation (1.7) we drop the insignificant variables TTSD and INEQ, and add regional dummy variables, for Asia, Sub-Saharan Africa, and Latin America. All of the structural variables (initial income, openness, resource abundance, investment rate, and bureaucracy) remain significant, even after the inclusion of regional dummy variables. Only the Sub-Saharan Africa dummy variable is significant, with a negative coefficient of -2.14 , meaning that Sub-Saharan African countries ceteris paribus grew less rapidly by 2.14 percent per year during 1971-89. The magnitude of the resource effect remains about the same as in the other regressions, with a coefficient in this case of -5.617 .

Although the regressions in Table 1 are exploratory, and thus we are somewhat hesitant to stress a structural interpretation, we do think the results are informative about the following general points. First, whatever the exact nature of the adverse effect of natural resource abundance on economic growth, the evidence suggests that it is not simply a proxy for bureaucratic inefficiency or protectionism, since these are measured directly through BUR and SOPEN. It also seems that the adverse effect is not operating mainly by lowering investment rates, since the negative correlation is maintained even after controlling for investment rates in the regression. Further, our failure to find any association between terms-of-trade volatility and growth leads us to downplay this effect as a possible channel for the primary export effect. Our failure to find any association between inequality and growth may result from measurement problems and a limited sample, or more simply from the fact that inequality has no direct effects on growth once we control for trade policy and bureaucratic inefficiency. In any event, we have little empirical basis to pursue this channel further in this paper. Therefore, we will proceed in this paper to look for indirect effects

\footnotetext{
${ }^{4}$ We note that other studies have reached different conclusions regarding the effects of volatility and inequality on growth. Since these questions are not the main concern of this paper, we refer the reader to two recent examples: Alesina and Rodrik (1994) and Ramey and Ramey (1994).
} 
operating through investment, trade policy, and bureaucratic policy, as well as other effects not related to these variables.

We have also checked the robustness of the resource effects on growth in several other ways, including the sensitivity of the regression results to outliers and alternative measures of primary resource intensity. One of the salient features of our data is that two oil-economies, Oman and Saudi Arabia, have very high shares of primary exports in GDP. They also have low growth, with Oman at 0.691 percent per year and Saudi Arabia at -0.682 percent per year, so that their presence in the regressions would tend to strengthen the estimated negative SXP effect. However, they also have missing values for several other variables, so that the results across different specifications would be sensitive to whether these countries have dropped in or out of the sample. To lessen this instability across samples, we have dropped both countries from the regressions in Table 1. We stress that this omission pushes our results towards a smaller measured adverse effect of natural resources on growth. That is, the effect would be even stronger with these countries included.

There are four other oil-intensive economies that are not in our sample because GDP data is not available for the full 1970-1989 period: Bahrain, Iraq, Kuwait, and the United Arab Emirates. Their growth rates for the maximum-available time periods are presented in Table 2, along with growth for Oman and Saudi Arabia. Note that the four omitted economies have negative growth rates. Indeed, Kuwait and the United Arab Emirates have such low growth rates that it is hard to take the data at face value. We suspect that these low growth rates are due in part to index number problems and measurement problems associated with large changes in relative prices between oil and other sectors, as well as labor migration into and out of these countries. For the purposes of this paper, it suffices to note that the six oil-intensive economies that we exclude have low growth, so that their inclusion would, if anything, strengthen the negative association between resource intensity and growth. ${ }^{5}$

We also investigated more formal techniques for assessing the sensitivity of our regressions to

\footnotetext{
${ }^{5}$ Average growth for 12 other oil-intensive economies in our sample was 1.395 , while average growth for the 6 in the excluded group was -2.889 .
} 
outliers. For this we follow some of the procedures described in Belsley, Kuh and Welsch (1980, p. 28) and Bollen and Jackman (1990, pp. 256-266). The basic idea is to exclude observations that have extremely high residuals and "leverage" on the regression results. This is particularly important in this context, since all countries have an equal weight in the regressions, whether they are a tiny or large economy. Therefore, we wanted to guard against the dependence of our results on a handful of tiny economies. The leverage of an observation is a multivariate measure of the distance of it's $X$ values from the means in the sample. Belsley, Kuh and Welsch recommend a statistic, which they call DFITS, that combines these two into one measure, (DFITS=r/((h/(1-h) $\left.)^{\wedge}(1 / 2)\right)$ and further suggest excluding an observation if DFITS exceeds $2(k / n)^{\wedge}(1 / 2)$. In the formulas above, $r$ is the residual, $h$ is the leverage, $k$ is the number of regressors and $\mathrm{n}$ is the sample size. In regression 1.2 in table 1 , we found that Trinidad and Tobago had a DFITS value about two times higher than this threshold and about two times higher than the next highest country in the sample. Trinidad and Tobago's growth was 0.738 , below the crosscountry mean of 1.431, and it had a high resource-intensity in 1971. Because we did not want the results to be too sensitive to a single observation, we also omitted Trinidad from the sample in all of the regressions in Table 1.

A third way we checked for robustness was to try alternative measures of primary resource intensity. In Table 3 we go back to the growth regression with initial income, openness and primary export intensity, and try three additional measures of resource intensity. The first regression in table 3, denoted 3.1 , is simply a replication of regression 1.2 , with SXP measuring resource intensity. The next measure of resource intensity is SNR, which measures the share of mineral production in GDP in 1971. This is constructed using country-specific production data from the U.S. Bureau of Mines for the top twenty-three minerals in 1971. These production figures were then valued at U.S. import prices and divided by the U.S. dollar value of GDP to obtain SNR. We can see from regression 3.2 that mineral production is also negatively associated with subsequent growth. Our third measure of resource intensity is PXI71, the fraction of primary exports in total exports in 1971 (rather than the value of primary exports relative to GDP, which is SXP). Our fourth measure is the log of land area per person in 1971. Regressions 3.3 and 
3.4 show that both are also negatively associated with subsequent growth. ${ }^{6}$

Our preferred measure of resource intensity is SXP. It has better coverage of primary production than SNR, which measures only minerals and fuel production. In addition, we suspect that measures of primary exports have less measurement error than the Bureau of Mine's estimates of mineral production in 1971, especially for poorer countries. ${ }^{7}$ We prefer SXP to PXI71 mainly because the intersectoral and political economy effects of natural resources should depend on the weight of those resources in total income (that is, GDP) rather than total exports. Finally, we prefer SXP to land area per person because land is not a very precise measure of primary production, though land abundance tends to be correlated with resource abundance. Therefore, we use land area per person as an instrument in a two-stage least squares regressions later in the paper.

The four figures ( 2 through 5 ) display the partial association between each of these measures of primary resource intensity and economic growth. These figures correspond to the regression coefficients reported in Table 3. According to these coefficient estimates, the magnitudes are as follows. An increase in SXP by one standard deviation is associated with a change (reduction) of subsequent growth of -0.74 percent per year. Similar one-standard-deviation increases in SNR and PXI71 are associated with changes in growth of, respectively, -0.81 percent per year and -0.63 percent per year. Since land intensity is measured in logarithms, a doubling of the land to population ratio is associated with a change in subsequent annual growth of -0.54 percent per year.

A fourth way to check robustness is to see if SXP remains significant in regression specifications

We also experimented with preliminary data developed at the World Bank, that attempts to measure the productive wealth of the world's economies, and to allocate that wealth among human capital, physical capital, and natural resources. We used the proportion of natural resource wealth in total productive wealth as a measure of resource abundance. As with the other measures, a high proportion of resource wealth is associated with slower economic growth, holding constant other relevant variables.

${ }^{7}$ We note that estimates of mineral reserves only seem to be available for oil and gas and a few major minerals. We did not find reserve data with sufficient resource and country coverage to be useful for this paper. Moreover, experts at the U.S. Bureau of Mines report that reserve estimates for many countries and minerals are simply a fixed multiple of production anyway, so that they may not have much more information than the production figures. 
of other studies. To look at this, we have replicated regressions from four previous empirical studies: Barro (1991), DeLong and Summers (1991), King and Levine (1993), and Mankiw, Romer and Weil (1992). In tables 8 through 12 we present the results. Each table contains the replication of the original regression in the first column and regressions with the new variables in subsequent columns. The new variables include the SXP variable mentioned above as well as the SOPEN variable from Sachs and Warner (1995).

In table 8 we show that SXP and SOPEN remain significant when included in the Barro (1991) specification, with t-ratios of -2.374 and 5.346 respectively. The two main changes from the original regression are first that the human capital variables appear less significant, and second, that investment is no longer significant. In the third regression we drop the insignificant regressors from the second regression and, instead of the political variables, add the rule of law index (measured in 1982) used recently in Keefer and Knack (1995) and Barro (1995). The index itself is highly significant; and SXP and SOPEN also remain significant.

In table 9 we ask how the new variables perform in the presence of the financial variables of King and Levine (1993). The original study considered four different measures of financial deepening; and we have estimated regressions with all four. In table 9 we illustrate a typical result with the LLY variable, which measures total banking system liabilities plus currency as a ratio to GDP. The general results is that the regressions prefer the SXP and SOPEN variables to the financial deepening variables. For example, in regression (2) the t-ratios on LLY, SXP and SOPEN are, respectively, 1.35, -2.95 , and 3.92. Note also that the human capital variable is again no longer significant. In regression (3) we try the initial value for LLY during our sample (1970), to mitigate problems stemming from reverse causality, and also find that it is not significant.

In table 10 we go back to estimation of the Solow model, as in Mankiw, Romer, and Weil (1992). To match the original specification, we re-measure the dependent variable as growth per economically active population rather than growth per person (economically active is assumed to be within the ages 15 through 64). In these regressions we continue to find that SXP and SOPEN are significant. The main 
change from the original specification is that population growth is no longer significant.

In table 11 we re-examine the hypothesis in De Long and Summers $(1991,1992)$ that growth is significantly related to the share of investment expenditures on machinery and equipment. We replicate their basic result in the first column: a significant coefficient on EQUIP and an insignificant coefficient on NES. In the third regression, we update their regression using the latest available growth data (version 5.6 of Summers and Heston, 1991) and find that the equipment variable is no longer significant in the presence of SXP and SOPEN.

From this brief review of other studies, our conclusion is that natural resource intensity and openness represent additional explanations for cross country growth that have not been considered by other studies. In general, these two variables remain significant in the presence of variables from other studies.

Although most of our evidence from the 1970-1989 period suggests a negative, statistically significant, partial association between primary resource intensity and growth, there are a few cases where the evidence is somewhat weaker. First, we tend to find that when investment is dropped from the growth regressions in Table 1, and bureaucracy is included, the SXP coefficient becomes insignificant, although still negative. Part of the reason for this result is that use of the bureaucracy variable eliminates about a third of the countries from the sample. And the bureaucracy variable is itself sometimes insignificant (see regression 1.6 for example). Second, the SNR variable is also insignificant in some regressions, but this result is sensitive to the presence of Botswana, Oman or Saudi Arabia in the sample. Botswana is a fast-growing resource intensive country while, as mentioned, the other two are slow growing resource-intensive countries. We choose not to stress these results because of our preference for the SXP variable (we believe SNR has more significant measurement problems). Overall, in terms of strength of empirical results, we have found the strongest results with the PXI71 variable, followed by SXP and then SNR. We have not extensively investigated the performance of the land-intensity variable.

Another way to approach the evidence is to try to identify cases of high-growth, resourceabundant economies, which would be counter-examples to our general proposition. Are there developing 
economies that are in the top quartile of resource abundance (measured by SXP, for example) and that have sustained high levels of growth? We find only two cases of developing countries (defined as 1971 income $<\$ 5,000$ per capita on a PPP basis) that were in the top quartile on $S X P$, and had sustained per capita growth of greater than or equal to 2.0 percent per annum for the period 1970-92. These countries are Malaysia and Mauritius. (Botswana would also probably be included but we are missing observations on SXP). The fact that there are only two such cases is, of course, striking, since the top quartile of SXP includes 18 developing countries. Moreover, these two exceptions are very illuminating. Both are very open economies. Both relied on virtually complete free trade, at least in the sense of zero-tariff Export Processing Zones to stimulate labor-intensive manufacturing exports. Both have had their growth sustained by the very rapid development of such exports. Thus, even in these cases, it is manufacturing exports rather than resource-led growth that accounts for the sustained high levels of economic growth. 


\section{Section 3. Pathways connecting resource-intensity and growth}

In this section we try to assess some of the pathways behind the inverse association between resource-intensity and growth. Guided by the results in table 1 as well as our priors, we postulate a simple empirical model. We view this model as a starting point for exploration, rather than as a definitive structural model of the pathways from resource abundance to growth.

$$
\begin{gathered}
\text { G7089= } \alpha_{0}+\alpha_{1} * S X P+\alpha_{2} * \text { SOPEN }+\alpha_{3} * I N V 7089+\alpha_{4} * B U R+\alpha_{5} * L G D P 70+\varepsilon_{1} \\
\text { INV7089= } \beta_{0}+\beta_{1} * L P I P 70+\beta_{2} * B U R+\beta_{3} * S O P E N+\beta_{4} * S X P+\varepsilon_{2} \\
\text { SOPEN }=\theta_{0}+\theta_{1} * S X P+\theta_{2} * S X P^{2}+\theta_{3} * L A N D+\varepsilon_{3} \\
\text { BUR }=\eta_{0}+\eta_{1} * S X P+\eta_{2} * L G D P 70+\varepsilon_{4} \\
\text { LPIP7O }=Y_{0}+Y_{1} * S X P+Y_{2} * L G D P 70+Y_{3} * S O P E N+\varepsilon_{5}
\end{gathered}
$$

The numbers of these equations correspond to regressions in the various tables. For example, the first equation above is given the number 6.2 because our preferred estimates are reported in Table 6 , regression 2. Similarly, the estimates of the second equation, number 6.4, are in Table 6, regression 4, and so forth. The only additional variable in this set of equations is LPIP70, which is the log of the ratio of the investment deflator to the overall GDP deflator in 1970 . This variable measures the price of investment goods, relative to overall prices. Several recent studies, for example, Warner (1994), and Taylor (1994), have found this or similar variables to be significant determinants of investment rates, with a higher price of investment goods associated with a lower rate of investment relative to GDP. Both price indexes, for investment goods and for the GDP deflator, are taken from version 5.6 of the Summers and Heston data.

These equations are meant to summarize several hypotheses about the link between resource 
wealth and growth. One hypothesis is that high natural resource abundance leads to increased rentseeking and corruption, which would show up in the measure of bureaucratic efficiency (equation 4.3). Remember that BUR is a composite index, built upon assessments of the degree of corruption, red tape, and judicial independence in the country. A low value of BUR -- that is, a high degree of bureaucratic inefficiency -- may depress growth directly (equation 6.2) or indirectly by depressing investment demand (equation 6.4). A second hypothesis is that high resource wealth has encouraged developing countries to pursue protectionist, state-led development strategies, as they try to combat the Dutch Disease effects of the resource abundance (equation 4.2). This inward-looking development results in lower investment rates (equation 6.4) and/or low growth rates directly, even controlling for investment rates (equation 6.2). A third hypothesis is that countries with higher natural resource abundance would have higher overall demand and higher relative prices of non-traded goods. This might affect the relative prices of investment goods (equation 4.5), with effects on investment rates (equation 6.4) and growth (equation 6.2). A final hypothesis is that high resource abundance leads to increased aggregate demand that shifts labor away from high learning-by-doing sectors and thus depresses growth in labor productivity, as in the Dutch Disease cum learning model in Appendix A of this paper. This effect, as well as further unspecified effects, may be captured by the SXP variable that enters directly in the growth equation, after controlling for trade policy and bureaucracy.

Clearly this is an oversimplified model, with particularly inadequate explanations for BUR and SOPEN. We present the results merely as an initial foray into a more structural assessment of the pathways from SXP to growth. We present the findings in four tables. Table 4 contains ordinary least squares estimates of the equations linking SXP to investment, openness, bureaucracy, and some other intermediate variables that might affect growth. Table 5 presents the reduced-form growth regressions implied by our set of equations. Table 6 presents instrumental variables estimates of the growth and investment equations. And Table 7 summarizes our best-estimates of the magnitude of the direct and indirect effects.

We have already found tentative support for the idea that bureaucratic efficiency is positively 
associated with growth (as in Mauro, 1995). That is, BUR is statistically significant in regression 1.4, 1.5, and 6.2., though the variable is sometimes statistically insignificant when other variables are also included in the regression (see regression 1.6 or 6.1 ). At the same time, however, the primary resource effect does not appear to work through the bureaucracy effect. There is only weak evidence that primary resource intensity is associated with poorer bureaucratic quality, though admittedly both the bureaucracy and resource variables are measured with considerable error. The estimate of $\eta 1$ in regression 4.3 has a tratio of only -1.7 . Second, our estimate of the effect of bureaucratic quality on investment is also somewhat weak. When we estimate the investment equation by ordinary least squares (regression 4.1) we find a positive but insignificant effect of BUR on INV; when we estimate the investment equation by instrumental variables (regression 6.4) we get the same result.

If we proceed to examine the point estimates, ignoring the statistical insignificance, the impact of SXP on growth via BUR is small. This is seen in Table 7 where we report the estimated effect of SXP on growth via BUR to be -0.883 (bottom of the table) and the effect through investment to be -0.366 . These numbers should be multiplied by the size of the change in SXP to calculate the partial effect of SXP via BUR on growth. For example, if SXP rises by one standard deviation (0.1344), the indirect effect on growth, working through reduced bureaucratic efficiency, would reduce annual growth by only one-tenth of a percentage point $(0.1344 *-0.883=-0.1187)$.

We find stronger evidence for indirect effects of SXP working through the extent of trade openness. First, we postulate, and find supporting evidence, for a U-shaped relation between openness (measured as SOPEN, on the $y$-axis) and resource intensity (measured as SXP, on the $x$-axis). Our reasoning is as follows. Resource abundance squeezes the manufacturing sector, as in the Dutch Disease. In almost all countries, the squeeze of manufactures provokes some protectionist response that aims to promote industrialization despite the Dutch Disease effects. For the most highly resourceendowed economies, however, such as the oil-rich states of the Middle East, the natural resource base is so vast that there is no strong pressure to develop an extensive industrial sector (other than in oil-based sectors such as petrochemicals and refining). Thus, for the most extreme resource-based cases, 
openness to trade (SOPEN) would tend to be high. The overall effect would therefore be a U-shaped relationship between SXP and SOPEN.

There is statistical support for this idea in regression 4.2 , where we find a negative estimated coefficient on the level of SXP and a positive coefficient on SXP2. The dependent variable SOPEN, is a fraction that ranges between 1 (if a country was open for the whole period 1965-1989) and 0 (if a country was never open). The estimated trough of the " $U$ " is when the share of primary exports in GDP equals 0.327 . For countries below that value -- which is almost all countries in the sample - higher primary exports tend to promote economic closure (that is, a low value of SOPEN). Above that threshold, higher SXP tends to promote openness. Two interesting examples on the positive part of the "U" are Malaysia and Saudi Arabia. These countries are extremely resource rich, and have also had a long tradition of open trade. Note that for the regressions explaining SOPEN, Saudi Arabia is included in the sample, unlike in the growth regressions for which Saudi Arabia is dropped. This is because Saudi Arabia is a particularly important observation for testing the possible non-linear effects of SXP on SOPEN. If we exclude Saudi Arabia, we still find the "Un" pattern in the regression results, but the estimated coefficient on $S X P^{2}$ is no longer statistically significant.

Since the vast majority of our countries have SXP values on the negatively sloped part of the "U" relation, we evaluate the effect of SXP growth via SOPEN at the mean of SXP (0.1282), along the negatively sloped part of the U-shaped relation. When we evaluate the effect of SXP on growth via SOPEN, we find that the effect on annual growth of a one-standard deviation increase in SXP is just under one-half of a percentage point $\left(0.1344^{*}-3.171=-0.4262\right)$.

We also find evidence for additional channels, as we summanize in Table 7. If we add up all the effects in Table 7 that involve the openness variable in some way, we find that an increase in SXP of one standard deviation reduces annual growth by just over one-half of a percentage point $\left(0.1344^{*}-(3.171\right.$ $+1.292+0.365)=-0.6489$ ). Indeed, by our estimates, the openness effects appear to be the only indirect effect of SXP that is quantitatively important. We also should mention that while we find evidence that higher relative prices of investment goods depress investment demand (equation 6.4), we find little impact 
of natural resource abundance on relative investment prices (equation 4.5).

The direct effect of SXP on growth is given by the estimated value for $\alpha 1$ in equation 6.2 . Since investment is endogenous in the growth equation, we prefer the instrumental variables estimates of the growth equation in Table 6. As shown, the estimated coefficient on SXP ranges from -5.2 to

-7.7. These estimates imply that an increase in SXP of one standard deviation is associated with a direct effect on growth of between -0.70 and -1.03 percent per year. This is much larger than any of the indirect effects taken individually, and is even larger than the sum of the estimated indirect effects. We also solve our set of equations for the reduced form, and present estimates of the reduced forms in Table 5. The first estimated equation, 5.1 , is an estimate of the growth regression when we substitute for investment. Apart from showing that the relative investment price does not significantly affect growth, this equation does not add to our conclusions. The other regressions are presented to show that the signs of the reduced form coefficients are as expected given our model; beyond this, we do not draw any additional substantive conclusions from these estimates.

Our main conclusion is that the estimated direct effect of SXP on growth is about twice as large as all the indirect effects combined. Moreover, of these indirect effects, our estimates indicate that the indirect effect operating through openness is by far the largest. These results lend modest support to the view that the dynamic Dutch disease effects we emphasize in the growth model in appendix $A$ are quantitatively important. However, it may also be the case that the normal downward bias in estimated regression coefficients, due to measurement errors in the independent variables, serve to depress the estimated indirect effects more than the direct effects. Of course, we cannot precisely separate true effects from measurement bias with the data we have at hand.

\section{Section 4. Summary and Conclusions.}

In our view, this paper has documented a statistically significant, inverse, and robust association between natural resource intensity and growth over the past twenty years. It is robust in the sense that it remains significant in cross-country growth regressions after controlling for a large number of additional variables that other studies have claimed to be important in explaining cross-country growth. The list of 
additional variables includes initial GDP, trade policy, investment rates, terms of trade volatility, inequality, and the effectiveness of the bureaucracy. We also find that the effect remains when we add regional dummy variables and introduce alternative measures of natural resource abundance. A striking "nonparametric" confirmation of the findings is the very few cases of resource-abundant developing countries that sustained even 2 percent per annum growth during 1971-92: only Malaysia and Mauritius, out of 18 countries.

These results can be interpreted in the context of three literatures. Many of the ideas in the theoretical literature on endogenous growth are difficult to test; but in the cases where they can be tested, endogenous growth ideas have not found strong support in the data. To the extent that such models contain the general idea that the industrial structure matters to growth, our results are at least mildly supportive. More specifically, our results are consistent with the view that a key division that matters for endogenous growth effects is tradeable manufacturing versus natural resource sectors. The paper therefore also provides some guidance, previously lacking, as to the identity of the sectors where endogenous growth effects might be present. Our results also support a dynamic version of earlier Dutch disease ideas. In addition, since the formal Dutch disease literature does not model growth effects specifically, we have also tried to close a formal gap in the literature by bringing an endogenous growth mechanisms into a model with Dutch disease features.

Finally, these results may be placed in the context of the empirical literature on the determinants of cross-country growth rates. We continue to find, as have many other studies, that there is evidence for conditional convergence, as suggested by neoclassical models of economic growth, since the estimated coefficients on initial GDP are always significantly negative. We also find that trade policy matters enormously for growth and for convergence, as summarized by our SOPEN variable (and related results in Sachs and Warner (1995)).

Although this paper does find evidence for a negative relation between natural resource intensity and subsequent growth, it would be a mistake to conclude that countries should subsidize or protect nonresource-based as a basic strategy for growth. First, although the results here using highly aggregated 
data are suggestive, they are far from definitive. Second, as argued in Sachs and Warner (1995), the evidence from the recent past suggests that there are simpler and more basic policies that can be followed to raise national growth rates, especially open trade. Third, the welfare implications of resource abundance can be quite different from the growth implications. Resource abundance may be good for consumption even if not good for growth; policies might be good for GDP growth, while reducing real consumption. Put differently, government policies to promote non-resource industries would entail direct welfare costs of their own, and these could easily be larger than the benefits from shifting out of natural resource industries. ${ }^{8}$ Therefore, we regard the issue of appropriate growth-oriented policies for resourceabundant countries to be an open and important topic for further analysis.

B Nor should our results be taken to deny that there are benefits from good policies regarding natural resource exploitation. Compare, for example, the experiences of the primary producers in Asia, namely Malaysia, Indonesia and Thailand with those in Africa (see Roemer, 1994). 
Table 1. Partial Associations Between Growth (1970-89) and Primary Resource Intensity (1971) Dependent Variable: G7089

(1.1)

(1.2)

(1.3)

(1.4)

(1.5)

(1.6)

\begin{tabular}{|c|c|c|c|c|c|c|}
\hline LGDP70 & $\begin{array}{c}0.398 \\
(1.831)\end{array}$ & $\begin{array}{c}-0.643 \\
(-2.701)\end{array}$ & $\begin{array}{c}-1.042 \\
(-4.080)\end{array}$ & $\begin{array}{c}-1.921 \\
(-6.243)\end{array}$ & $\begin{array}{l}-1.853 \\
(-5.902)\end{array}$ & $\begin{array}{c}-1.891 \\
(-5.220)\end{array}$ \\
\hline SXP & $\begin{array}{c}-6.920 \\
(-3.280)\end{array}$ & $\begin{array}{c}-4.687 \\
(-2.568)\end{array}$ & $\begin{array}{c}-5.019 \\
(-2.892)\end{array}$ & $\begin{array}{c}-7.806 \\
(-2.942)\end{array}$ & $\begin{array}{c}-7.104 \\
(-2.603)\end{array}$ & $\begin{array}{c}-5.925 \\
(-2.263)\end{array}$ \\
\hline SOPEN & & $\begin{array}{c}3.477 \\
(6.567)\end{array}$ & $\begin{array}{c}2.661 \\
(4.761)\end{array}$ & $\begin{array}{c}2.167 \\
(3.845)\end{array}$ & $\begin{array}{c}1.935 \\
(3.211)\end{array}$ & $\begin{array}{c}2.246 \\
(3.664)\end{array}$ \\
\hline INV7089 & & & $\begin{array}{l}10.318 \\
(3.362)\end{array}$ & $\begin{array}{c}9.085 \\
(2.679)\end{array}$ & $\begin{array}{c}9.686 \\
(2.822)\end{array}$ & $\begin{array}{c}13.665 \\
(4.018)\end{array}$ \\
\hline BUR & & & & $\begin{array}{c}0.370 \\
(3.153)\end{array}$ & $\begin{array}{c}0.320 \\
(2.544)\end{array}$ & $\begin{array}{c}0.166 \\
(1.137)\end{array}$ \\
\hline TTSD & & & & & $\begin{array}{c}-0.018 \\
(-1.070)\end{array}$ & $\begin{array}{c}-0.006 \\
(-0.301)\end{array}$ \\
\hline INEQ & & & & & & $\begin{array}{c}0.067 \\
(1.776)\end{array}$ \\
\hline Constant & $\begin{array}{c}-0.846 \\
(-0.490)\end{array}$ & $\begin{array}{c}5.537 \\
(3.192)\end{array}$ & $\begin{array}{c}6.991 \\
(4.103)\end{array}$ & $\begin{array}{l}12.472 \\
(6.304)\end{array}$ & $\begin{array}{l}12.605 \\
(6.368)\end{array}$ & $\begin{array}{c}12.067 \\
(5.454)\end{array}$ \\
\hline $\begin{array}{l}\text { RBAR2 } \\
\text { N-K } \\
\text { SIGMA }\end{array}$ & $\begin{array}{l}0.130 \\
95\end{array}$ & $\begin{array}{l}0.420 \\
89\end{array}$ & $\begin{array}{l}0.481 \\
88\end{array}$ & $\begin{array}{l}0.597 \\
56\end{array}$ & $\begin{array}{l}0.598 \\
56\end{array}$ & $\begin{array}{l}0.617 \\
40\end{array}$ \\
\hline
\end{tabular}

Notes: T-ratios appear below the coefficients. 
Table 2. Growth Rates of Six Oil-Economies Not In Our Sample

\begin{tabular}{lcc}
\hline Bahrain & $1975-1988$ & -1.2633 \\
Iraq & $1970-1987$ & -1.8761 \\
Kuwait & $1980-1989$ & -8.0123 \\
Oman & $1970-1989$ & 0.6910 \\
Saudi Arabia & $1970-1989$ & -0.6820 \\
United Arab Emirates & $1980-1989$ & -6.1937 \\
Average & & -2.8894 \\
\hline
\end{tabular}

Source: Penn World Tables, version 5.6 (update of data in Summers and Heston, 1991). 
Table 3. Associations between Growth and Resource Intensity using Alternative Measures of Resource Intensity

Dependent Variable: G7089
(3.1)
(3.2)
(3.3)
(3.4)

\begin{tabular}{lcccc}
\hline & & & & \\
LGDP70 & -0.643 & -0.637 & -0.781 & -0.451 \\
& $(-2.701)$ & $(-2.821)$ & $(-3.245)$ & $(-2.165)$ \\
SOPEN & 3.477 & 3.680 & 3.026 & 2.783 \\
& $(6.576)$ & $(7.270)$ & $(5.852)$ & $(5.780)$ \\
SXP & -4.687 & - & - & - \\
& $(-2.568)$ & & & - \\
SNR & - & -3.742 & - & - \\
& & $(-2.405)$ & & \\
PXI71 & - & - & -2.189 & -0.545 \\
& & & $(-3.083)$ & $(-4.919)$ \\
LAND & - & - & - & 0.497 \\
RBAR2 & & & & 103 \\
N & 0.420 & 0.450 & 0.418 & \\
SIGMA & 89 & 100 & 97 & \\
\hline
\end{tabular}

Notes: T-ratios appear below the coefficients. 
Table 4. Indirect Effects

Dependent Variables:

INVESTMENT OPENNESS BUREAUCRACY VOLATILITY INV PRICE SXP

(4.1)

(4.2)

(4.3)

(4.4)

(4.5)

(4.6)

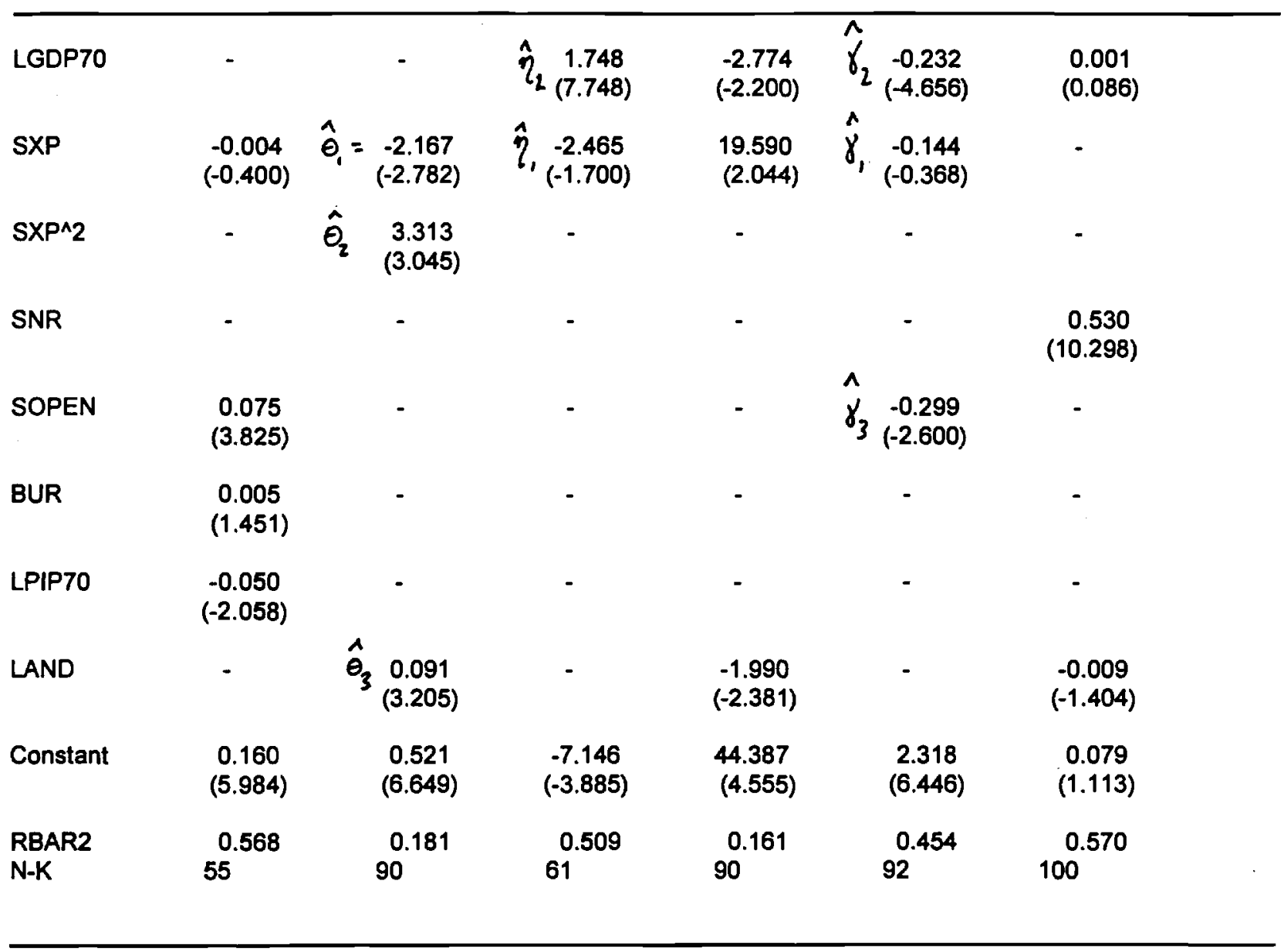

Notes: T-ratios appear below the coefficients. 
Table 5. Reduced-Form Growth Regressions

Dependent Variable: G7089

(5.1)

(5.2)

(5.3)

(5.4)

\begin{tabular}{|c|c|c|c|c|}
\hline LGDP70 & $\begin{array}{c}-1.714 \\
(-5.350)\end{array}$ & $\begin{array}{c}0.361 \\
(1.641)\end{array}$ & $\begin{array}{c}0.398 \\
(1.831)\end{array}$ & $\begin{array}{c}0.248 \\
(1.226)\end{array}$ \\
\hline SXP & $\begin{array}{c}-8.070 \\
(-2.862)\end{array}$ & $\begin{array}{c}-12.844 \\
(-2.187)\end{array}$ & $\begin{array}{l}-6.920 \\
(-3.280)\end{array}$ & - \\
\hline SXP^2 & - & $\begin{array}{l}14.444 \\
(1.081)\end{array}$ & - & - \\
\hline SOPEN & $\begin{array}{c}2.828 \\
(5.235)\end{array}$ & - & - & - \\
\hline BUR & $\begin{array}{c}0.330 \\
(2.749)\end{array}$ & - & - & - \\
\hline LPIP70 & $\begin{array}{c}-0.664 \\
(-1.075)\end{array}$ & - & - & - \\
\hline SNR & - & - & - & $\begin{array}{c}-0.701 \\
(-0.670)\end{array}$ \\
\hline LAND & - & - & - & $\begin{array}{l}-0.603 \\
(-4.751)\end{array}$ \\
\hline $\begin{array}{l}\text { RBAR2 } \\
\mathrm{N}\end{array}$ & $\begin{array}{c}0.541 \\
57\end{array}$ & $\begin{array}{l}0.132 \\
95\end{array}$ & $\begin{array}{l}0.130 \\
95\end{array}$ & $1_{112}^{0.206}$ \\
\hline
\end{tabular}

Notes: T-ratios appear below the coefficients. 
Table 6. Instrumental Variables Estimates of the Growth and Investment Equations

IV Estimates of Growth Eqn. - - - - IV Estimates of Investment Eqn. --
(Dependent Variable: G7089)
(Dependent Variable: INV7089)
(6.1)
(6.2)
(6.3)
(6.4)

\begin{tabular}{|c|c|c|c|c|}
\hline LGDP70 & $\begin{array}{c}-1.898 \\
(-5.116)\end{array}$ & $\hat{\alpha}_{S}^{\prime}-2.023$ & $\begin{array}{c}-1.291 \\
(-3.937)\end{array}$ & - \\
\hline SXP & $\begin{array}{c}-5.893 \\
(-2.229)\end{array}$ & $\begin{array}{ll}\hat{\alpha}_{1} & -7.663 \\
& (-2.830)\end{array}$ & $\begin{array}{c}-5.225 \\
(-2.921)\end{array}$ & $\begin{array}{ll}\hat{\beta}_{4} & -0.050 \\
(-0.464)\end{array}$ \\
\hline SOPEN & $\begin{array}{c}2.207 \\
(2.883)\end{array}$ & $\begin{array}{lc}\hat{\alpha}_{2} & 1.820 \\
& (2.257)\end{array}$ & $\begin{array}{c}2.151 \\
(3.067)\end{array}$ & $\begin{array}{cc}\hat{\beta}_{3} & 0.055 \\
& (2.300)\end{array}$ \\
\hline INV7089 & $\begin{array}{l}14.236 \\
(1.922)\end{array}$ & $\hat{d}_{s} \begin{array}{l}13.484 \\
(1.687)\end{array}$ & $\begin{array}{l}16.754 \\
(2.798)\end{array}$ & - \\
\hline BUR & $\begin{array}{c}0.161 \\
(1.027)\end{array}$ & $\hat{\alpha}_{y} \begin{array}{c}0.358 \\
(2.960)\end{array}$ & - & $\begin{array}{ll}\hat{\beta}_{2} & 0.011 \\
& (1.538)\end{array}$ \\
\hline TTSD & $\begin{array}{c}-0.006 \\
(-0.310)\end{array}$ & - & - & - \\
\hline INEQ & $\begin{array}{c}0.067 \\
(1.777)\end{array}$ & - & - & - \\
\hline LPIP70 & - & - & - & $\begin{array}{ll}\hat{\beta} & -0.052 \\
(-2.070)\end{array}$ \\
\hline $\begin{array}{l}\text { RBAR2 } \\
N-K\end{array}$ & $\begin{array}{l}0.617 \\
40\end{array}$ & $\begin{array}{l}0.583 \\
56\end{array}$ & $\begin{array}{l}0.454 \\
88\end{array}$ & $\begin{array}{l}0.539 \\
56\end{array}$ \\
\hline
\end{tabular}

Notes: T-ratios appear below the coefficients. The endogenous variable in the growth regressions is INV7089. The instruments are LPIP70, SNR and LAND. The endogenous variable in the investment regression is BUR. The instrument is LGDP70. 
Table 7. Summary of Estimated Direct and Indirect Effects of Primary Resource Intensity on Growth

$\begin{array}{lll}\text { Pathway } & \begin{array}{l}\text { Relevant } \\ \text { Parameters } \quad \text { Estimate }\end{array}\end{array}$

Direct

Through openness

Through investment price and investment

Through bureaucracy and investment

Through openness and investment

Through investment

Through openness, investment price and investment

Through bureaucracy

Sum of the above $\alpha 1$

$-7.663$

$\alpha 2(\theta 1+2 \theta 2$ SXP)

$-3.171$

$\alpha 3 \beta 1 \gamma 1$

0.101

$Y 1$ not significant

$\alpha 3 \beta 2 \eta 1$

$-0.366$

$\eta 1, \beta 2$ not significant

$\alpha 3 \beta 4$

$-0.674$

B4 not significant

$\alpha 3 \beta 1 \gamma 3(\theta 1+2 \theta 2$ SXP) $\quad-0.365$

$\alpha 4 n 1$

$-0.883$

$\eta 1$ not significant

Notes. The estimated $\alpha$ 's are taken from regression 6.2 in table 6 . The estimated $\beta$ 's are taken from regression 6.4 in table 6. The estimated $\theta$ 's are taken from regression 4.2 in table 4 . The estimated $\gamma$ 's are taken from regression 4.5 in table 4. And the estimated $\eta$ 's are taken from regression 4.3 in table 4 . The term $(\theta 1+2 \theta 2 S X P)$, is evaluated at the mean of SXP of 0.1282 . When evaluated at the mean it equals -1.742 . 
Table 8. Estimation of Barro (1991) with Variables from this Paper

Dependent Variable: $\mathbf{G 7 0 8 9}$

(1)

SXP

DTT7189

GDP70

$-0.292$

$(-2.503)$

SEC70

4.617

(1.751)

PRI70

$-0.264$

$(-0.213)$

GVXDXE

$-3.550$

$(-0.815)$

$-0.157$

$(-0.146)$

$-2.444$

$(-1.322)$

$-0.017$

$(-0.031)$

(2)

$(-2.374)$

2.897

(5.346)

1.172

(1.983)

$-0.536$

$(-5.942)$

$-1.745$

$(-4.897)$

5.381

(2.734)

1.566

(1.401)

$-11.366$

$(-2.935)$

$-12.672$

(-2.938)

$-1.571$

$(-1.980)$

ASSASSP

12.787

(3.066)

3.324

$(0.931)$

$-0.886$

$(-0.619)$

$-0.133$

$(-0.324)$

INV7089

RL82

Adj. R2

N-K

Mean D.V.

SIGMA
-

0.218
77
1.668
1.900
1.465

(0.799)

-

1.752

(3.081)

-

$-3.687$

2.040)

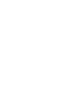

\begin{tabular}{lccc} 
REVCOUP & -0.157 & -1.571 & - \\
& $(-0.146)$ & $(-1.980)$ & \\
ASSASSP & & -0.886 & - \\
& -2.444 & $(-0.619)$ & - \\
PPI70DEV & $(-1.322)$ & -0.133 & \\
& -0.017 & $(-0.324)$ & - \\
INV7089 & $(-0.031)$ & 3.324 & \\
& 12.787 & $(0.931)$ & 0.542 \\
RL82 & $(3.066)$ & - & $(3.620)$ \\
& - & & 0.526 \\
Adj. R2 & & 0.637 & 66 \\
N-K & 0.218 & 65 & 1.596 \\
Mean D.V. & 17 & 1.530 & 1.382 \\
SIGMA & 1.668 & 1.297 & \\
\hline
\end{tabular}

Notes: T-ratios are in parentheses. The first regression reports our replication of regression 24 in Barro (1991). The replication is close but not exact, due to a slightly different sample (1970-89 rather than 1960-1989) and revisions in the Summers and Heston data (we use version 5.6). The other variables are as follows. SEC7O is the secondary school enrollment rate. PRI70 is the primary school enroliment rate. GVXDXE is the ratio of real govemment consumption spending (excluding spending on the military and education) to real GDP. REVCOUP is the average number of revolutions and coups over the period 1970-1985. ASSASSP Is the average number of assassinations per million persons over the period 1970-1985. PPI70DEV measures the deviation of the (log) price level of investment goods from the cross country mean in 1970. INV7089 is the mean ratio of real gross domestic investment (public plus private) to real GDP over the period 1970-1989. RL82 is the rule of law index in 1982, used in Keefer and Knack (1995, forthcoming) and Barro (1995). 
Table 9. Estimation of King and Levine (1993), with Variables from this Paper

Dependent Variable: GYP

(1)

(2)

(3)

\begin{tabular}{|c|c|c|c|}
\hline SXP & & $\begin{array}{c}-0.0536 \\
(-2.9458)\end{array}$ & $\begin{array}{c}-0.0504 \\
(-2.7132)\end{array}$ \\
\hline SOPEN & & $\begin{array}{c}0.0245 \\
(3.9248)\end{array}$ & $\begin{array}{c}0.0246 \\
(3.8633)\end{array}$ \\
\hline DTT7189 & & $\begin{array}{c}0.0032 \\
(0.6285)\end{array}$ & $\begin{array}{c}0.0032 \\
(0.6239)\end{array}$ \\
\hline LRGDP & $\begin{array}{c}-0.0051 \\
(-2.0235)\end{array}$ & $\begin{array}{c}-0.0076 \\
(-3.3243)\end{array}$ & $\begin{array}{c}-0.0077 \\
(-3.3095)\end{array}$ \\
\hline LSEC & $\begin{array}{c}0.0081 \\
(2.3006)\end{array}$ & $\begin{array}{c}0.0047 \\
(1.4452)\end{array}$ & $\begin{array}{c}0.0051 \\
(1.5389)\end{array}$ \\
\hline LLY & $\begin{array}{c}0.0334 \\
(2.3349)\end{array}$ & $\begin{array}{c}0.0138 \\
(1.3467)\end{array}$ & - \\
\hline LLY70 & - & - & $\begin{array}{c}0.0163 \\
(1.2049)\end{array}$ \\
\hline Constant & $\begin{array}{c}0.0490 \\
(0.0209)\end{array}$ & $\begin{array}{c}0.0666 \\
(3.6318)\end{array}$ & $\begin{array}{c}0.0679 \\
(3.6534)\end{array}$ \\
\hline $\begin{array}{l}\text { RBAR2 } \\
\text { N-K } \\
\text { Mean D.V. } \\
\text { SIGMA }\end{array}$ & $\begin{array}{c}0.2342 \\
79 \\
0.0164 \\
0.0193\end{array}$ & $\begin{array}{l}0.4377 \\
67 \\
0.0163 \\
0.0148\end{array}$ & $\begin{array}{c}0.4313 \\
66 \\
0.0164 \\
0.0150\end{array}$ \\
\hline
\end{tabular}

Notes: T-ratios are in parentheses. The regression in column (1) is our replication of the regression in appendix table VII of King and Levine (1993). LRGDP is the log of real GDP (from World Bank data to maintain consistency with the original study). LSEC is the log of the secondary school enrollment rate in 1970. LLY is the mean over the period 1970-1989 of liabilities of the banking system plus currency divided by GDP. LLY70 is the value of LLY in 1970. Regressions with the other financial variables in King and Levine give similar results: significant coefficients on SOPEN and SXP; insignificant coefficients on the financial variables. 
Table 10. Estimation of Mankiw, Romer and Well (1992), with Variables from this Paper

Dependent Variable: GEA7090

(1)

(2)

SXP

$(-2.210)$

SOPEN

DTT7189

LGDPEA70

GP7089

$-0.500$

0.038

$(-2.614)$

(0.145)

INV7089

15.308

8.958

(4.854)

Constant

0.591

0.044

(0.813)

(0.046)

RBAR2

N-K

Mean D.V.

0.333

110

83

1.282

1.580

Notes: T-ratios are in parentheses. The regression in column (1) matches the specification in table IV, page 426, of Mankiw, Romer, and Weil (1992). The results are close to the original, although with a different time period (197090, rather than 1960-85), a larger sample, (110 rather than 98) and updated data, they are understandably not identical. GEA7090 is average annual real growth per economically active person in 1970 (the economically active population is assumed to be the population between the ages of 15 and 65); LGDPEA is the log of real GDP per economically active person in 1970; GP7089 is population growth; INV7089 is the ratio of investment to GDP, averaged over the period 1970-1989. 
Table 11. Estimation of DeLong and Summers (1991), with Variables from this Paper

Dependent Variables:

$\begin{array}{cc}\text { GWG } & \text { GEA7089 } \\ 1970-85 & 1970-89\end{array}$

(1)

(2)

SXP

SOPEN

GWGAP

LFG

EQUIP

NES

Constant

RBAR2

$\mathrm{N}-\mathrm{K}$

Mean D.V.

SIGMA
$-0.082$

$(-3.445)$

0.030

(5.210)

0.023

0.038

(3.930)

(2.273)

0.243

(1.222)

$(-0.293)$

0.090

(1.163)

(3.485)

0.019

(0.542)

(1.590)

$-0.031$

$-0.023$

(-2.702)

$(-1.969)$

0.515

0.214

60

0.015

0.016
53

0.017

0.013

Notes: T-ratios in parentheses. The first regression is a replication of De Long and Summers using 1970-85 data rather than 1960-85. The results are close to regression 4, table 1, page 162, of De Long and Summers (1992). The first regression uses the growth data reported in the appendix of De Long and Summers (1991). The second regression uses the revised and updated growth data from version 5.6 of Summers and Heston (1991). The explanatory variables are GWGAP, the gap in GDP vis-a-vis the U.S. in 1970; LFG, labor force growth; EQUIP, the fraction of investment in producer's durable equipment; and NES, the fraction of investment in non-equipment and structures. 


\section{Appendix B: A Dynamic Dutch-Disease Endogenous Growth Model.}

The model is an overlapping-generations, endogenous growth model where people live two periods: working and receiving a wage in the first period; and retiring in the second period. In this appendix, we first describe the supply side and then the demand side. This is followed by a section that describes the equilibrium and the dynamic solution of the model and finally the main propositions about the effects of a resource boom on growth.

\section{Supply side}

The production side of the model has three sectors: a traded manufacturing sector, for which we use the superscript ' $m$ ', a non-traded sector, for which we use the superscript ' $n$ ', and a natural resource sector describes by ' $R$ ' or ' $r$ '. The natural resource sector produces a constant flow of natural resources in each period, which we denote by 'R'. Production in this sector employs no capital or labor, and the resource output can be sold on world markets at an exogenous world price of $p^{\prime}$. For convenience, we choose units of $R$ so that this price term need not appear in our equations. This model makes no distinction between resource booms that come about because of discoveries and resource booms that come about because of increases in resource prices.

In the two sectors that employ labor and capital, production functions are given by

$$
\begin{aligned}
& X^{m}=G\left(L^{m}, K^{m}\right) \\
& X^{n}=F\left(L^{n}, K^{n}\right)
\end{aligned}
$$

The source of growth in this model is labor-augmenting technical change. We introduce a human capital variable, ' $\mathrm{H}$ ', which can be thought of as the stock of knowledge in the economy. The key assumption is that the accumulation of knowledge is generated as a byproduct of employment in the traded manufacturing sector. This stock of knowledge raises the amount of effective labor by the same

amount in all sectors, not just the traded sector. Hence the variable $\mathrm{H}$ multiplies the employment variables in each of the production functions. Normalizing the total labor force to 1 , and letting the variable $\theta$, represent the share of labor in the traded sector, the production functions above may be written in the following way.

$$
\begin{gathered}
x^{m}=G\left(\theta H, K^{m}\right) \\
x^{n}=F\left((1-\theta) H, K^{n}\right)
\end{gathered}
$$

We further assume that these functions are homogenous of degree one and can therefore be written in intensive form as

$$
\begin{aligned}
& x^{m}=g\left(k^{m}\right) \\
& x^{n}=f\left(k^{n}\right)
\end{aligned}
$$


where lower case variables are denominated in units of effective labor. For example,

$$
k^{m}=\frac{K^{m}}{\theta H}, \quad k^{n}=\frac{K^{n}}{(1-\theta) H}
$$

Having defined $\theta$, the share of labor in the traded sector, we can now state explicitly the assumption that the accumulation of knowledge capital depends on the share of labor employed in the traded sector.

$$
H_{t}=H_{t-1}\left(1+\theta_{t-1}\right)
$$

Since the production functions can be written in intensive form, capital market equilibrium requires that capital is employed in each sector up to the point where the value marginal product of capital per effective worker equals the world real interest rate. There are no adjustment costs in achieving the desired capital stocks.

$$
\begin{gathered}
p^{n} f^{\prime}\left(k^{n}\right)=r \\
g^{\prime}\left(k^{m}\right)=r
\end{gathered}
$$

The price $p^{n}$ is the ratio of the price of the non-traded good to the price of traded manufactures. The price of manufactures is the numeraire and is thus set equal to 1 . The relative price $p^{n}$ is determined later in the model, but once determined, the equations immediately above will determine the equilibrium capital-labor ratios in each sector.

Competition and free entry in both sectors ensures that there are zero profits. These conditions are written below with $b(w, r)$ denoting the unit cost functions. For given values of the world real interest rate, these equations can be used to solve for the wage rate, $w$, and $p^{n}$ as functions of $r$ and the world price of the traded good, $\mathrm{p}^{\mathrm{m}}$, set to 1 below.

$$
\begin{aligned}
& p^{n}=b_{w}^{n}(w, r) w+b_{r}^{n}(w, r) r \\
& 1=b_{w}^{m}(w, r) w+b_{r}^{m}(w, r) r
\end{aligned}
$$

\section{Demand side}

Consumers solve the following inter-temporal consumption problem. Each generation works and receives a wage when young. It is also assumed in the background that the government obtains the revenue from sale of the natural resource and simply transfers this in lump-sum fashion to each member of the young generation. The variable ' $R$ ' below measures the size of this resource transfer per effective worker of the young generation. Consumers can save for retirement at the world rate of interest to spread consumption across time. 
$\operatorname{Max} U=\left[\ln \left(c_{t}^{m}\right)+\beta \ln \left(c_{t}^{n}\right)\right]+\delta\left[\ln \left(c_{t+1}^{m}\right)+\beta \ln \left(c_{t+1}^{n}\right)\right]$

s.t. $\quad c_{l}^{m}+p_{i}^{n} c_{t}^{n}+\frac{1}{1+r}\left(c_{t+1}^{m}+p_{t+1}^{n} c_{t+1}^{n}\right)=w_{t}+R_{t}$

This produces the following demand functions for each generation.

$$
\begin{aligned}
& \frac{c_{t}^{m}}{H_{t}}=c_{t}^{m}=\frac{1}{(1+\beta)(1+\delta)}\left(w_{t}+R_{t}\right) \\
& \frac{c_{t}^{n}}{H_{t}}=c_{t}^{n}=\frac{1}{p_{t}^{n}} \frac{\beta}{(1+\beta)(1+\delta)}\left(w_{t}+R_{t}\right) \\
& \frac{c_{t+1}^{m}}{H_{t}}=c_{t+1}^{m}=\frac{\delta(1+r)}{(1+\beta)(1+\delta)}\left(w_{t}+R_{t}\right) \\
& \frac{C_{t+1}^{n}}{H_{t}}=c_{t+1}^{n}=\frac{1}{p_{t+1}^{n}} \frac{\delta \beta(1+r)}{(1+\beta)(1+\delta)}\left(w_{t}+R_{t}\right)
\end{aligned}
$$

To obtain total demand for each good in any given period, we sum these demand functions across generations. A complication is that with human capital accumulation, the amount of effective labor is increasing in each period. Since we choose to express the quantities in terms of units of effective young workers, this means that we have to convert the expressions that are implicitly in units of old workers to units of young workers. Specifically, if $c^{\circ}$ is consumption of the old per old worker, then $H_{t \cdot 0} / H_{t} c^{\circ}$ would be consumption of the old, per young worker.

The equation below sums the demands across the two generations for the non-traded good in a given period. Total demand is expressed per units of effective young workers, with the term $1 / 1+\theta_{1-1}$ reflecting the adjustment from old to young workers.

$$
c_{t}^{n}=\frac{1}{p_{t}^{n}} \frac{\beta}{(1+\beta)(1+\delta)}\left[w_{t}+R_{t}+\frac{\delta\left(1+r_{t-1}\right)}{1+\theta_{t-1}}\left(w_{t-1}+R_{t-1}\right)\right]
$$

3. The equilibrium. sector.

The last equation needed to solve the model is that supply must equal demand in the non-traded 


$$
c_{i}^{n}=f\left(k^{n}\right)\left(1-\theta_{i}\right)
$$

The reason for the extra 1- $\theta$ term on the right of this equations is that $c^{n}$ is in units of young workers in the whole economy, but $f\left(k^{n}\right)$ is in units of young workers only in the non-traded sector, so $f()$ must be reduced to express the right hand side in units of total young workers. Substituting the expression for total non-traded demand from above, the non-traded equilibrium can be written explicitly as:

$$
\frac{1}{p_{t}^{n}} \frac{\beta}{(1+\beta)(1+\delta)}\left[w_{t}+R_{t}+\frac{\delta\left(1+r_{t-1}\right)}{1+\theta_{t-1}}\left(w_{t-1}+R_{t-1}\right)\right]-f\left(k^{n}\right)+f\left(k^{n}\right) \theta_{t}=0
$$

For latter reference it is convenient to write this function as:

$$
\phi\left(R_{r}, R_{t-1}, \theta_{t}, \theta_{t-1}\right)=0
$$

We first consider the solution to the model for the case where there is no natural resource production. Equations 11 and 12 determine the real wage and the relative price of non-traded goods for given values of $r$. Given the non-traded price, equations 9 and 10 then determine the equilibrium capital labor ratios in each sector. To determine $\theta$, note first that equation (21 or 22 ) above is a first order, nonlinear difference equation in $\theta$, so that we can define a steady state value for $\theta$ implicitly by $\phi\left(0,0, \theta^{s s}, \theta^{s s}\right)=0$. However, we now check to see if the dynamics that this equation implies for $\theta$ are locally stable. To see this we calculate

$$
\frac{d \theta_{t}}{d \theta_{t-1}}=\frac{\frac{1}{p_{t}^{n}} \frac{\delta \beta(1+r)}{(1+\beta)(1+\delta)\left(1+\theta^{s t}\right)^{2}}\left(w_{t}\right)}{f\left(k^{n}\right)}
$$

Local stability requires that this derivative lies between zero and one. The expression is clearly positive. It is also less than one, as can be seen in the following way. If one multiplies both numerator and denominator by $H(1-\theta)$, then the denominator equals total production in the non-traded sector. Referring back to equation 18 , the numerator becomes total consumption of non-traded goods by the older generation, multiplied by a term, $(1-\theta) / 1+\theta)$, which is less than one. Since total production must exceed consumption by the older generation, the denominator must exceed the numerator and the expression must be less than one.

Stability guarantees that although $\theta$ will not jump immediately to its new equilibrium following a shock, it will do so gradually in a step by step fashion. Furthermore, with $\theta$ following dynamic step-by-step adjustment, it can be seen from 8 that the human capital variable, $H$, will also follow dynamic step-by-step adjustment. Once $\theta$ has reached its new steady state value, $H$ will then grow continuously at the constant rate $\theta$.

Growth of $H$ then determines growth of other key variables. From the equations in 7 , once $H$ is growing at rate $\theta$ and $\theta$ itself is fixed at its steady state value, the capital stocks in the two sectors will also grow at rate $\theta$. Furthermore, since the production functions are homogenous of degree one, and both 
factors are growing at rate $\theta$, output in both sectors will grow at rate $\theta$.

To evaluate GDP growth we use the factor income decomposition of GDP.

$$
G D P=R+w H+r\left(K^{n}+K^{m}\right)
$$

Since all terms except $\mathrm{R}$ grow at rate $\theta$ in the steady state, it is clear that the non-resource economy also grows at rate $\theta$. Because of the presence of the non-growing resource sector however, total GDP grows at rate $\alpha \theta$, where $\alpha$ is the fraction of GDP in all sectors outside the natural-resource sector.

To evaluate effects on the level, as opposed to the growth, of GDP, we substitute for $K^{n}$ and $K^{m}$ in equation 23 and rearrange to obtain

$$
G D P=R+H(w+r)\left[k^{n}+\theta\left(k^{m}-k^{n}\right)\right]
$$

With the model described in the equations above, we can now establish the main propositions.

Proposition 1. Economies that experience a temporary resource boom. will have a lower rate of growth for several periods after the boom than otherwise identical economies with no resource boom.

This can be established by considering the effects of a one shot resource boom. Suppose $R_{1}$ is positive and all other $\mathbf{R}$ 's are $\mathbf{0}$. If all world prices are constant, during the period up to and including period $\mathbf{O}$ the share of labor in manufacturing and therefore the growth of the economy will be determined by $\theta^{s s}$. In period $1, \theta_{1}$ will be determined implicitly by $\phi\left(R_{1}, 0, \theta_{1}, \theta^{s s}\right)=0$. With the younger generation wealthier in period 1 because of the resource boom, as long as they wish to spend some of their increased wealth in the first period on non-traded goods, demand will rise and draw labor from the traded sector to the non-traded sector. That is, $\theta_{1}$ will be lower than $\theta^{s a}$. In period $2, \theta_{2}$ will be determined implicitly by $\phi\left(0, R_{1}, \theta_{2}, \theta_{1}\right)=0$. There is again a direct demand effect on non-traded goods in period 2 from the resource boom in period 1 . Now, the beneficiaries of the resource boom are the older generation. As long as they spend some of their higher wealth on non-traded goods in period 2, this direct demand effect will act to depress $\theta_{2}$ relative to $\theta^{3 s}$. But there is also a second effect in period 2 . That is, with a lower $\theta_{1}$, there will be less effective young in period 2 and demand by the wealthier old generation will carry a higher weight in economy-wide demand. This effect also serves to raise demand for the non-traded good relative to the case where there is no resource boom.

Since the magnitude of the direct demand effects in the two periods depend on preferences regarding inter-temporal consumption smoothing, we cannot establish which one is larger. Because of this, we cannot establish whether $\theta_{1}$ exceeds $\theta_{2}$, even though there is the additional effect depressing $\theta_{2}$ in period 2. But it is clear that $\theta_{2}$ will be less than $\theta^{*}$, because the direct demand effect cannot fall below 0 , and the indirect effect works to depress $\theta$. After period 2, the dynamics of $\theta$ take over and $\theta$ returns gradually to $\theta^{\text {ss. }}$. Overall, $\theta$ will fall below $\theta^{\text {ss }}$ for several periods after the resource boom in period 1 , and the economy will grow slower than similar economies without resource booms.

Proposition 2. The effect of a rise in the natural resource endowment in period 1 on the level of nonresource GDP in period 1 depends on the capital intensities of the two sectors.

This can be seen by differentiating the expression for GDP in equation 24 with respect to $R_{t}$. 


$$
\frac{\partial G D P_{1}}{\partial R_{1}}=1+H_{1}(w+r) \frac{\partial \theta_{1}}{\partial R_{1}}\left(k^{m}-k^{n}\right)
$$

The effect of a rise in $R_{1}$ on non-resource GDP is given by the second term on the right hand side. We know from proposition 1 that $d \theta_{1} / d R_{1}$ is negative. Hence non-resource GDP will initially rise with a rise in the resource endowment if the non-traded sector is more capital intensive than the traded sector, $k^{n}>k^{m}$.

\section{The Effect of a Rise in R.}

We can now walk through what happens when this economy has a one-shot increase in the natural resource, $R$, in period 1 . Recalling the equations from above, we have the factor income decomposition of total GDP,

$$
G D P=R+w H+r\left(K^{n}+K^{m}\right)
$$

and after substituting for $K^{n}$ and $K^{m}$ and rearranging, we have:

$$
G D P=R+H(w+r)\left[k^{n}+\theta\left(k^{m}-k^{n}\right)\right]
$$

The one-shot rise in $R$ will of course directly increase GDP in period 1, but it will also have a more subtle and prolonged effect on growth in subsequent periods. Let's suppose that the proceeds from the resource boom are transferred to the younger generation in period 1 . The increase in wealth will raise demand in period 1 , and some of the increased demand will fall on the non-traded good. This will draw labor from the manufacturing sector, that is, $\theta$ will decline. We can see from the definition of GDP above that the decline in $\theta$ will have a contemporaneous effect on the level of GDP depending on the capital intensities in the two sectors. For example, if the non-traded sector is more capital intensive than the manufacturing sector, then the rise in employment in that sector will raise GDP by more than the decline in employment in manufacturing will lower GDP.

The change in sectoral employment will also have a more prolonged effect on accumulation of human capital and future growth. With a lower $\theta_{1}$, human capital will be lower in period 2 than it would have been without the resource boom. Furthermore, even though the resource boom will have ended by period 2, the wealthier generation will still be living in period 2, and demand will still be higher than without the resource boom. This means that $\theta_{2}$ will again be lower than otherwise and human capital accumulation will again be lower in period 3 . Thereafter, as described above, $\theta$ will climb gradually back to the steady state level, but of course, human capital accumulation, physical capital accumulation, and growth will be slower in the intervening period.

It is possible then, that the full effect of the one-shot resource boom is to raise the level of GDP initially, but reduce the growth rate by enough that the level of GDP eventually falls below that of a nonbooming economy. This case of long-run immiseration as a result of a resource boom is illustrated in figure B1. Initially, both economies start with the same level and growth rate of GDP, so that the log of GDP follows the straight line between points $O$ and $A$. Then, at time $t_{0}$, the resource boom causes the level of GDP in one economy to rise immediately, say to point B. But the resource boom also ushers in a period of slower growth, so that it is possible for GDP to fall below that of the other economy, illustrated by point $C$. Starting at point $D$, the two economies again have the same growth rate, but the economy which formerly had the resource boom will have a permanently lower level of GDP. 


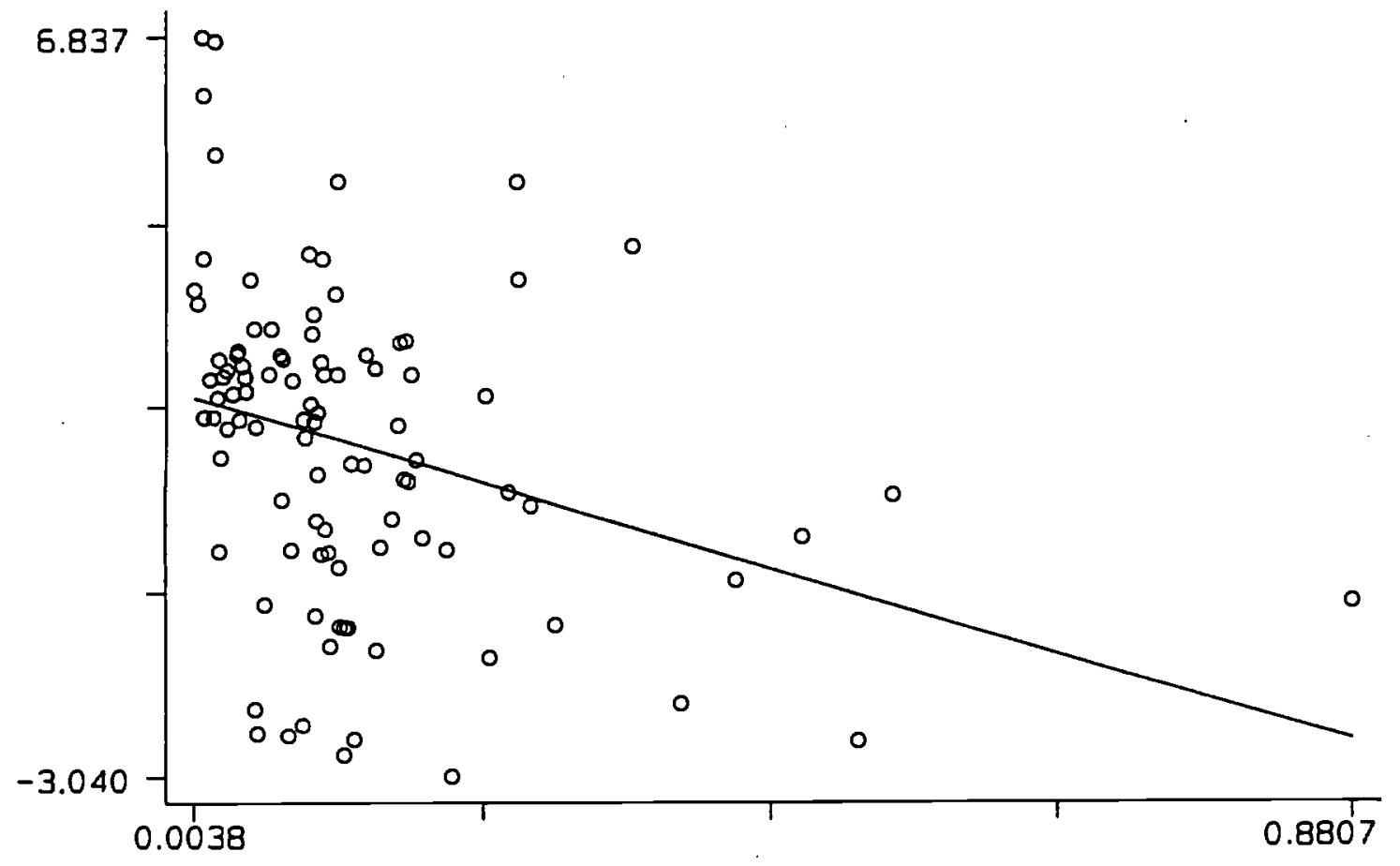

Figure 1. The simple association between growth per-capita between 1970 and 1989 (vertical axis) and the share of natural resource exports in GDP in 1971 (horizontal axis). The regression line has a slope of -5.2 and a t-ratio of -3.3 . 


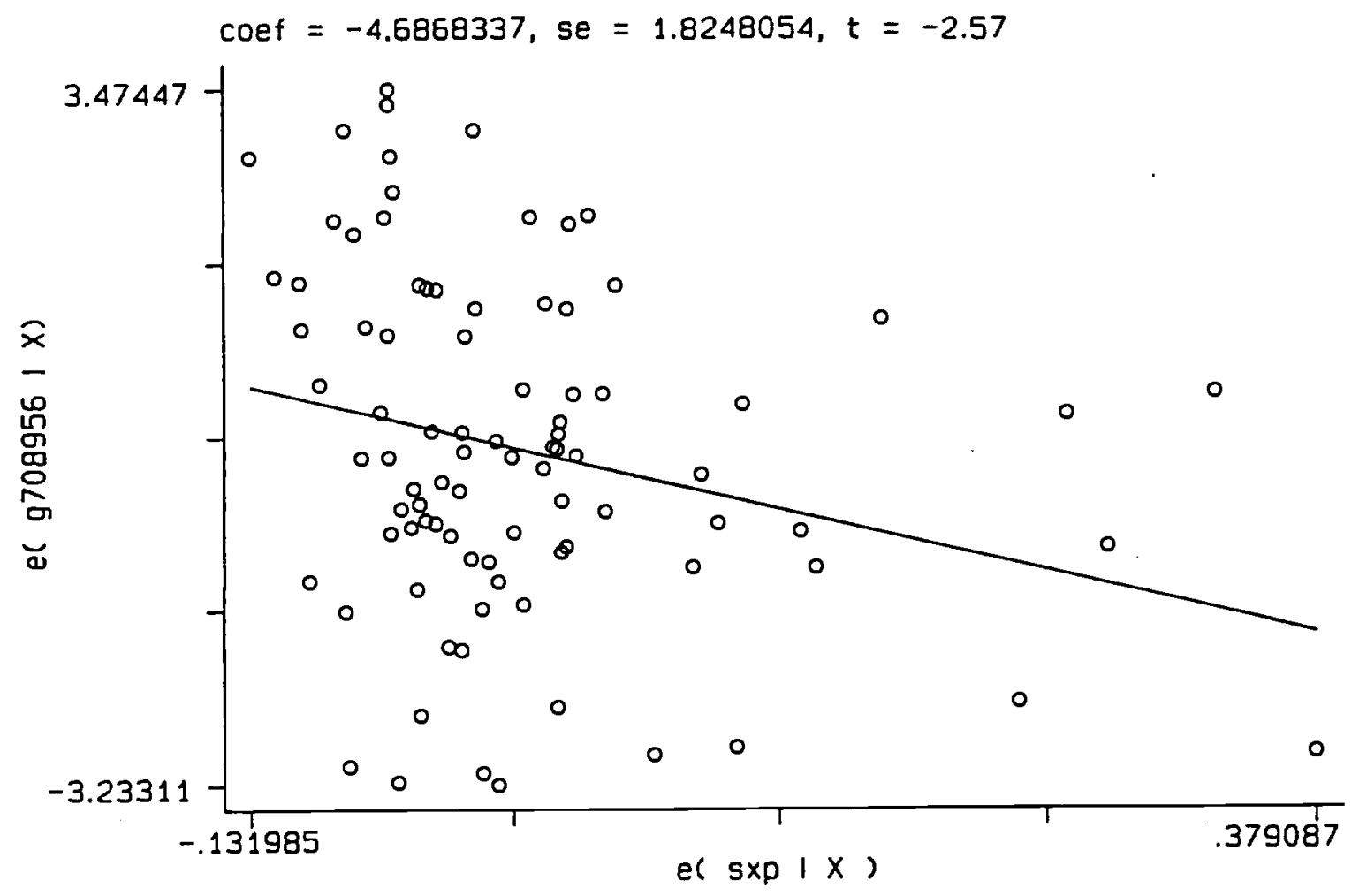

Figure 2. The partial association between growth per-capita between 1970 and 1989 (vertical axis) and the share of natural resource exports in GDP in 1971 (horizontal axis). The regression controls for initial income and SOPEN, and is reported as regression 3.1 in table 3. 


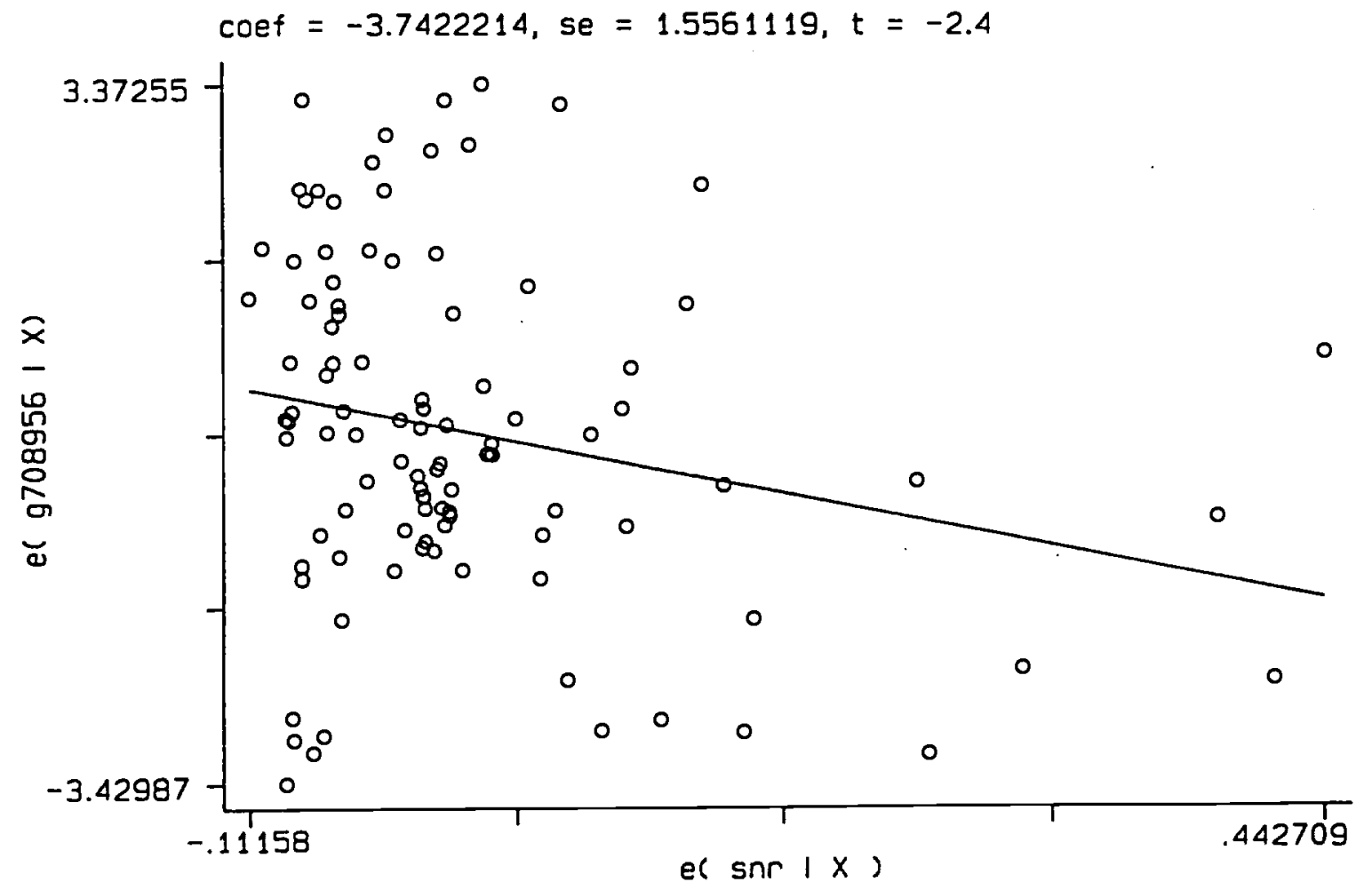

Figure 3. The partial association between growth per-capita between 1970 and 1989 (vertical axis) and the share of mineral production in GDP in 1971 (horizontal axis). The regression controls for initial income and SOPEN, and is reported as regression 3.2 in table 3. 


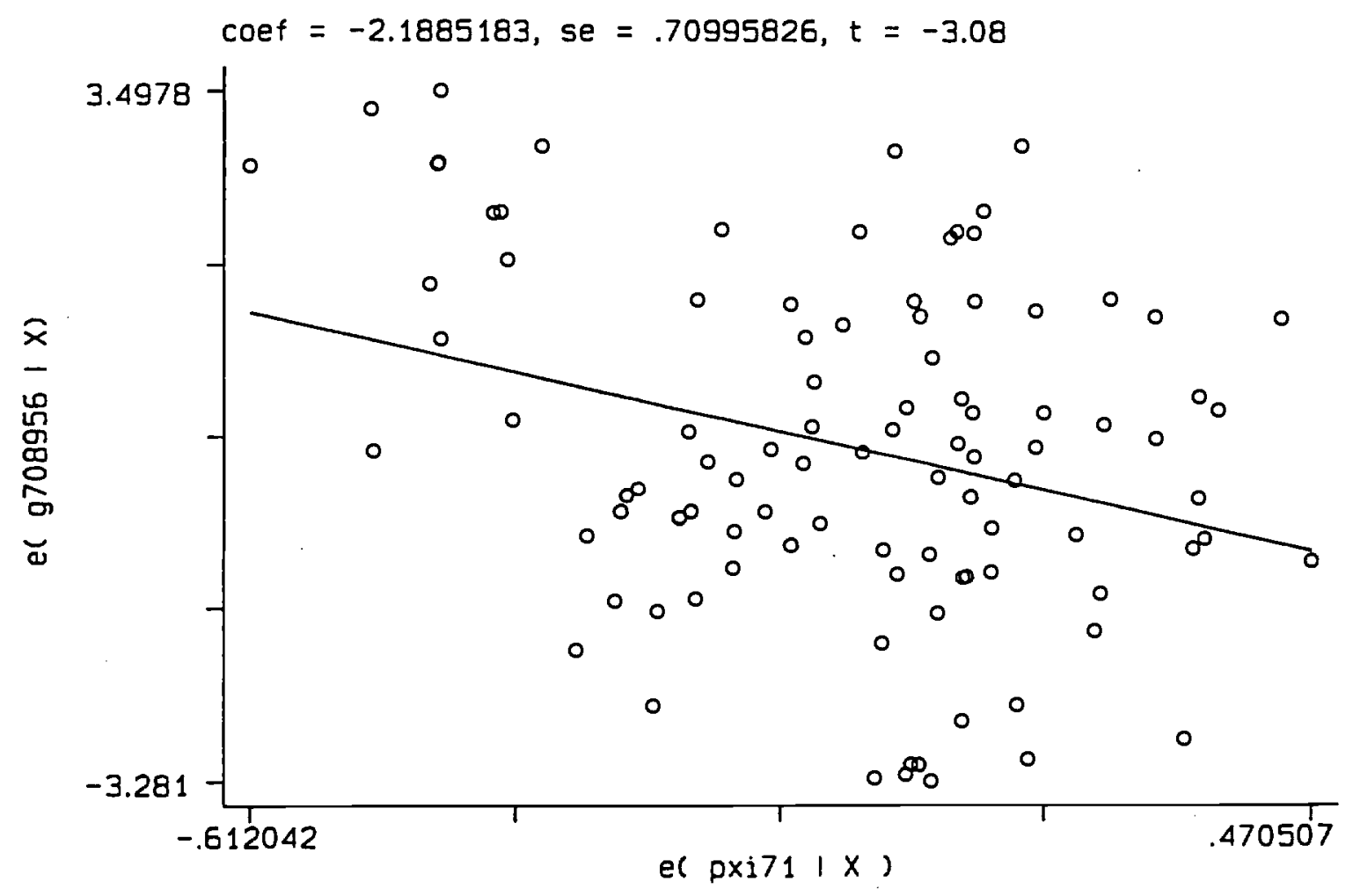

Figure 4. The partial association between growth per-capita between 1970 and 1989 (vertical axis) and the share of natural resource exports in total exports in 1971 (horizontal axis). The regression controls for initial income and SOPEN, and is reported as regression 3.3 in table 3. 


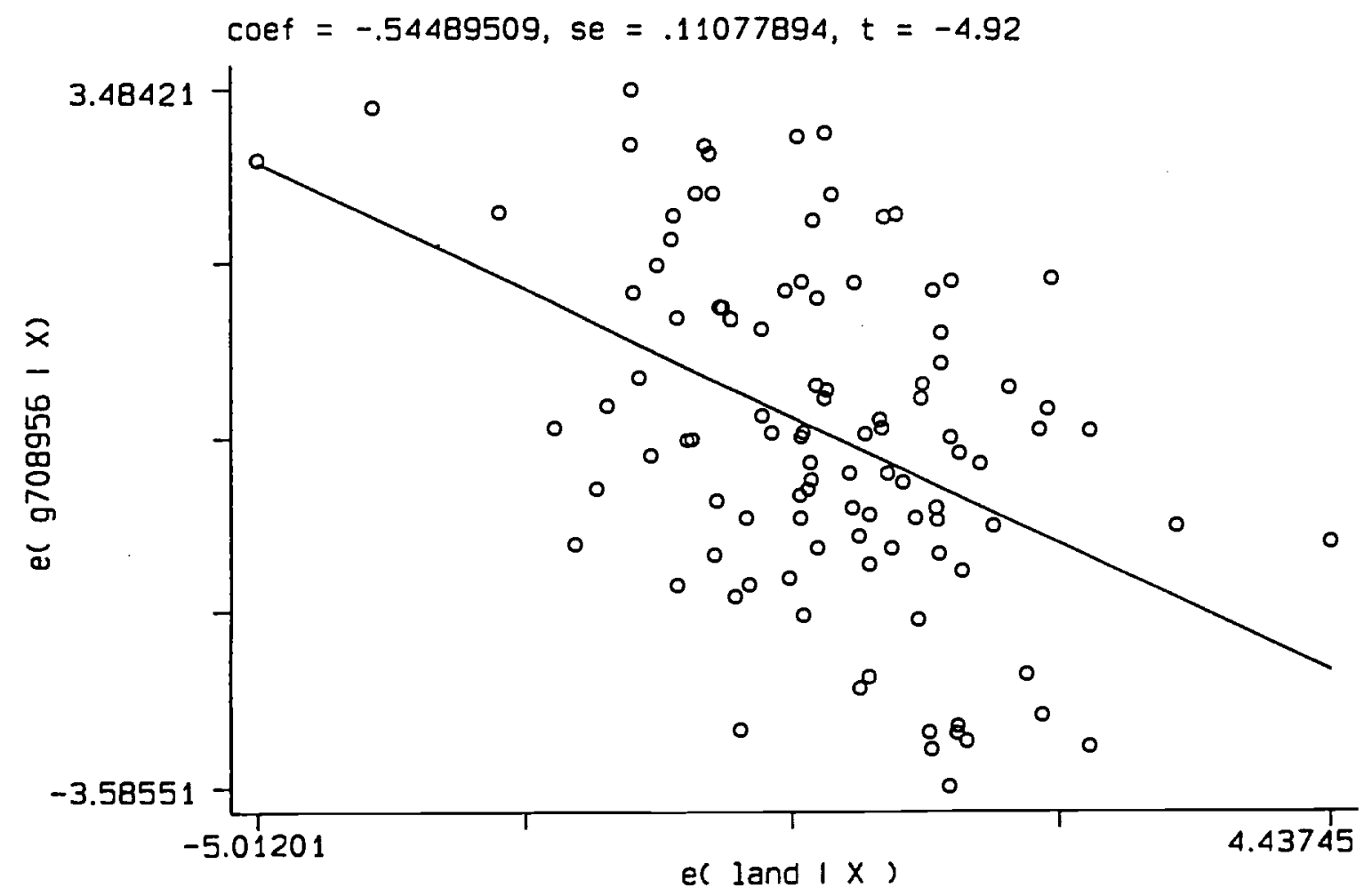

Figure 5. The partial association between growth per-capita between 1970 and 1989 (vertical axis) and the log ratio of land area to population in 1971 (horizontal axis). The regression controls for initial income and SOPEN, and is reported as regression 3.4 in table 3. 


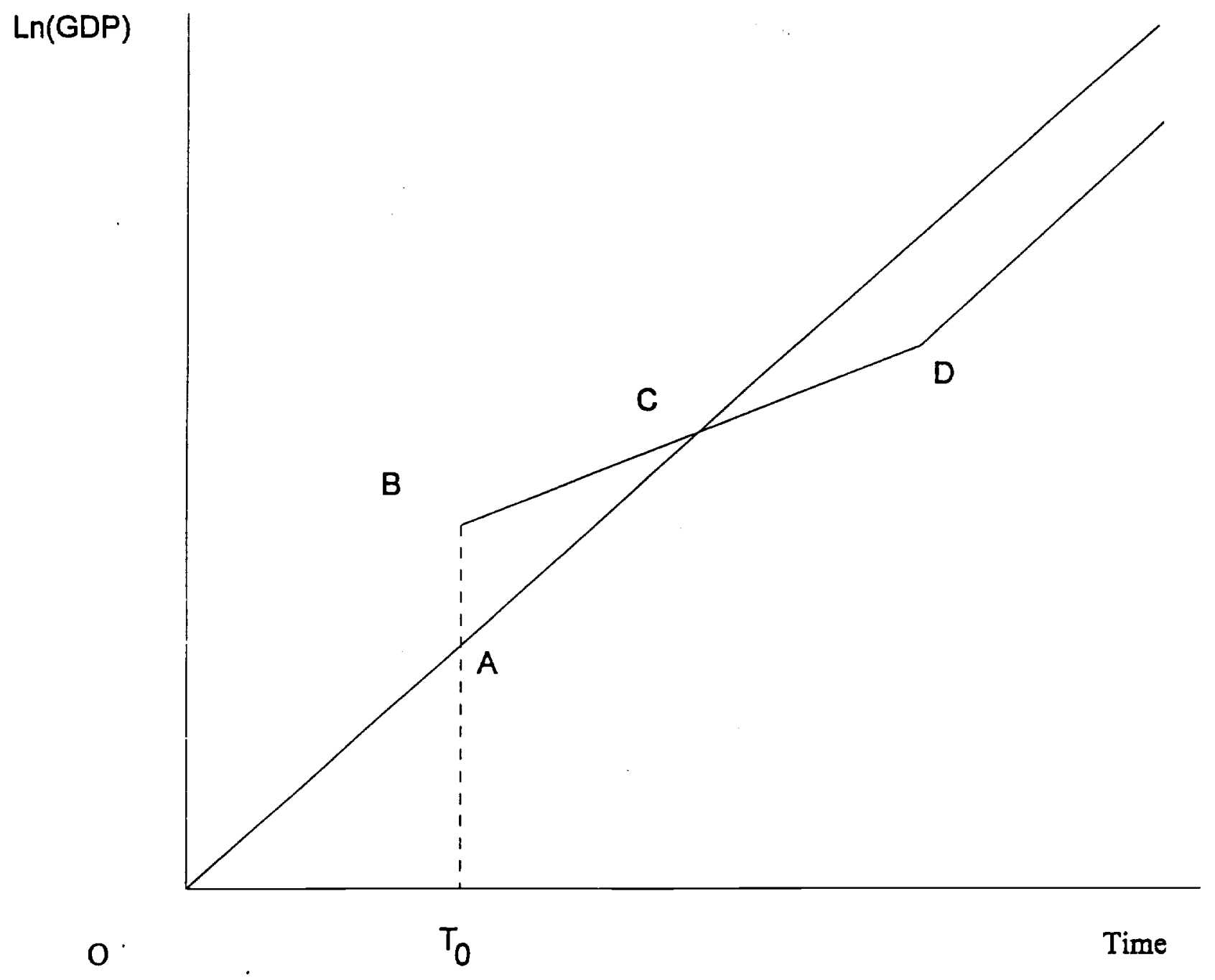

Figure B1 
LGDP70 Real purchasing power parity adjusted GDP per capita from Summers and Heston version 5.6 in 1970 (1985 International Prices).

LGDP89 Same variable for 1989.

G7089 Real per capita growth rate of GDP, per annum: G7089 = [LGDP89 - LGDP70]/19.

SXP Share of primary exports in GDP in 1971. Taken from the World Tables 1993 data diskette. Both numerator and denominator are measured in nominal dollars. The dollar GDP data in World Tables uses a smoothed exchange rate to convert local currency GDP to dollars. Primary exports are the sum of the categories 'non-fuel primary products' and 'fuels'. Non-fuel primary products cover SITC categories $0,1,2,4$, and 68 . Fuels cover SITC category 3 . These categories are from revision 1 of the SITC.

M73

The value of mineral production in 1973. This is taken from source 1 , (see below) which directly reports the value of mineral production (in million U.S. dollars) for the years 1968 and 1973, but only for those years and only for the top 38 countries.

Source 1: United States Bureau of Mines, 1974 Minerals Yearbook: Volume III Area Reports: International, U.S. Department of the Interior, Washington D.C. Table 4. p. 30. This is turn takes data from Annales des Mines, No. 12, December 1975 pp. 28-29.

M71 The value of mineral production in 1971. This is calculated by the authors from price and quantity data:

$$
M 71_{j}=\sum_{i=1}^{23} p_{i} * m q_{i J}
$$

The sum is over 23 minerals ( 1 index). Minerals were selected for this list if they were ranked in the top 23 in terms of value of production in 1973. In 1973, the value of total world production of these 23 minerals was $\$ 156,276$ million dollars. The value of world production of all minerals was $\$ 159,201$ million dollars. So these 23 minerals cover 98 percent of world production in 1973. (Source: 1974 Minerals Yearbook, table 5, p. 31.)

The price data are implicit U.S. import prices of each mineral, calculated by taking the ratio of real and nominal imports into the U.S. in 1971. These data are taken from the 1971 Minerals Yearbook.

The quantities are from real production data, by country and by minerals for the year 1971. This is taken from the 1973 minerals yearbook because it contains the last revisions for 1971 data. For each of the $\mathbf{2 3}$ minerals, the country-coverage is complete.

POP70 Population in 1970 (thousands). Taken from Summers and Heston, version 5.6. 
GNPD71 GNP in dollars in 1971. For most countries, the data are taken from the World Tables data diskette, World Bank, 1993.

SNR The share of mineral production in GNP in 1971.

SNR $=(M 71 * 1,000 /($ GNPD71*POP70) $)$

LAND The log of the ratio of total land area to population in 1971. The land data are from table 1 of the FAO's 1971 Production Yearbook. For a few countries with incomplete data in the 1971 Yearbook, we use the data in the 1993 Production Yearbook.

SOPEN The fraction of years during the period 1965-1990 in which the country is rated as an open economy according to the criteria in Sachs and Warner (1995).

BUR The bureaucratic efficiency index in Mauro (1995). A higher rating means a more efficient bureaucracy. This is the simple average of three indexes compiled by Business International for the period 1980-1983. The three component indices are an index rating the efficiency of the Judiciary, an index for lack of red tape, and an index for lack of corruption. The data are reported in Appendix 3, p. 708 of Mauro (1995).

TTSD The standard deviation of the log of the external terms of trade index (ratio of export price index to import price index) over the period 1971-1989. Calculation by the authors based on terms of trade data in World Tables, 1993 data diskette.

INEQ Ratio of the income share of the top 20 percent of the income distribution to the bottom 20 percent of the income distribution. Data are taken from p. 178 and p. 203 of the Human Development Report, 1995. These data in turn use estimates reported in the World Bank's World Development Report 1994. The data cover the period 1980-1992.

LPIP70 The log of the ratio of the investment deflator to the GDP deflator in 1970. The deflators are the PPP deflators reported in version 5.6 of the Penn World Tables (see Summers and Heston (1991) for a description of an earlier version of this data). In the Summers and Heston notation, LPIP70 = In(PI/P), using 1970 data.

GAP70 The log of the ratio of a countries real GDP in 1970 to that of the USA in 1970 (using the GDP data in version 5 of the Summers and Heston data).

GWB Real growth rate of GDP, 1971-1989, per annum, in constant local currency, (not percapita). Source: World Bank, World Tables, 1993.

AGRIC70 The ratio of value added in Agriculture to total GDP in 1971. Source: World Bank, World Tables, 1993.

LAGRIC70 The percentage of the labor force in Agriculture in 1971. Source: World Bank, World Tables, 1993.

PYR70 Average years of primary schooling in the total population over age 25. Source: Barro and Lee, 1994.

SYR70 Average years of secondary schooling in the total population over age 25. Source: Barro and Lee, 1994. 
HYR70 Average years of higher schooling in the total population over age 25. Source: Barro and Lee, 1994.

PXI71 Primary export intensity in 1971. Ratio of exports of SITC (revision 1) categories 0, 1, 2, 3,4 , and 68 to total exports in 1971, with both the numerator and denominator expressed in nominal dollars. Source: World Bank, World Tables, 1993, for all countries except Taiwan and South Africa. Data for Taiwan was obtained from the Taiwan Statistical Data Book, 1992. Data for South Africa was obtained from Bulletin of Statistics, The Republic of South Africa, Pretoria, Dec. 1972 and June 1992, (exports of raw diamonds and gold were included). Singapore was given a value of 0.01 based on GDP and labor force data indicating that Singapore produced no primary products itself but simply re-exported primary products produces elsewhere. The data for Bangladesh is for 1972 rather than 1971. The data for Cameroon was set to 1.0 - it exceeded 1.0 using the published data.

PX189 Same variable for 1989.

DTT7189 Change in the log of the external terms of trade between 1971 and 1989. DTT7189= $L N(T 789)-L N(T T 1)$, where $T$ is the ratio of a U.S. dollar export price index $(1987=100)$ to an import price index in similar units. Source: World Bank, World Tables, 1993, and the Taiwanese and South African sources listed above.

MSGDP The ratio of value added in manufacturing to total value added in 1970. Source: World Bank, World Tables, 1993.

XMXP The log of the ratio of manufacturing exports to primary exports in 1971. Source: World Bank, World Tables, 1993.

HRNR The log of average years of primary schooling times the labor force divided by total land area (sq. $\mathrm{km}$ ).

EQUIP Spending on equipment investment as a fraction of GDP, average between 1970-85. Source: DeLong and Summers (1991), Appendix IV: Data Table XVI, page 495.

LLY70 The ratio of the liabilities of financial intermediaries plus currency in circulation to GDP in 1970. Source: King and Levine (1993).

BANK70 Ratio of deposit money bank domestic assets to the sum of deposit money bank domestic assets and central bank domestic assets in 1970. Deposit money bank domestic assets is the sum of IFS lines 22a through 22f. Central bank domestic assets is the sum of IFS lines 12a through 12f. Source: King and Levine (1993). (a.k.a. BTOTI).

PRIVATE70 Ratio of claims on the non-financial private sector to total domestic credit in 1970 (excluding credit to deposit money banks). Source King and Levine (1993). (a.k.a. DCPTI).

PRIVY70 Ratio of claims on the non-financial private sector to GDP in 1970. Source: King and Levine (1993). a.k.a. DCPYI.

LLY Mean of LLY for the period 1970-1989.

BANK Mean of BANK for the period 1970-1989. 
PRIVATE Mean of PRIVATE for the period 1970-1989.

PRIVY Mean of PRIVY for the period 1970-1989.

SEC70 Secondary school enrollment rate. Source: Barro and Lee, 1994.

PRI70 Primary school enrollment rate. Source: Barro and Lee, 1994.

GVXDXE Ratio of real government 'consumption' spending net of spending on the military and education to real GDP. Source: Barro and Lee, 1994, who in turn used Summers and Heston v. 5.5.

REVCOUP Number of revolutions and coups per year, averaged over the period 1970-1985. Source Barro and Lee, 1994.

ASSASSP Number of assassinations per million population per year, 1970-1985. Source: Barro and Lee, 1994.

PPI70DEV The deviation of the log of the price level of investment (PPP I / Xrate relative to the U.S.) from the cross country sample mean in 1970. Source: Authors calculation based on the PISH5 price data in Barro and Lee, 1994.

INV7089 Ratio of real gross domestic investment (public plus private) to real GDP, averaged over the period 1970-1989. Source: Barro and Lee, 1994, who in turn used Summers and Heston v. 5.5.

GYP Growth of per-capita GDP, averaged over the period 1970-1989. Source: King and Levine (1993), who in turn use the World Bank National Accounts.

GWG Growth in real GDP per worker, 1970-1985. Source: DeLong and Summers (1991), data appendix.

LFG Growth in the labor force. Source: DeLong and Summers (1991), data appendix.

NES Fraction of GDP spent on non-equipment and structures, averaged over the period 19701985. Source: DeLong and Summers (1991), data appendix.

GEA7089 Growth per economically active population. Real GDP is taken from the Penn World Tables, version 5.6 , and economically active population (defined as population between the ages 15 and 64), is taken from the World Tables 1994 data diskette.

RL82 An index based on survey data to measure the extent "to which the citizens of a country are willing to accept the established institutions to make and implement laws and adjudicate disputes". Higher values mean that there are "sound political institutions, a strong court system, and provisions for an orderly succession of power." Lower values mean that there is "a tradition of depending on physical force or illegal means to settle claims." Range is 0-6. Data was purchased from Political Risk Services. This variable was assembled by the Center for Institutional Reform and the Informal Sector, from hard copies of the"International Country Risk Guide," a monthly publication of Political Risk Services. The variable is for 1982. Also described in Knack, Stephen and Keefer, Philip (1995, forthcoming). "Institutions and Economic Performance: Empirical Tests using 
Alternative measures of Institutions." Economics and Politics (also IRIS Working Paper \#109). 


\section{References}

Auty, R.M. Resource-Based Industrialization: Sowing the Oil in Eight Developing Countries. New York: Oxford University Press, 1990.

Baldwin, R.E. Economic Development and Export Growth: A Study of Northern Rhodesia, 1920-1960. Berkeley and Los Angeles, CA: University of California Press, 1966.

Barro, R. and J. Lee. "Panel Data Set Cross Countries" Data Diskette, January 1994.

Barro, R. and X. Sala-I-Martin. Economic Growth. New York: McGraw-Hill, Inc, 1995.

Belsley, D.A., Kuh, E. and R.E. Welsch. Regression Diagnostics. New York: John Wiley and Sons, 1980.

Berge, K. et al. "Trade and Development Strategy Options for the Poorest Countries: A Preliminary Investigation." Institute of Development Studies Working Paper 12, December, 1994.

Bollen, K.A. and R.W. Jackman. "Regression Diagnostics: An Expository Treatment of Outliers and Influential cases." In Modern Methods of Data Analysis, ed J. Fox and J.S. Long, 257-291. Newbury Park: Sage Publications, 1990.

DeLong, J.B., and J.G. Williamson. "Natural Resources and Convergence in the Nineteenth and Twentieth Centuries", Unpublished paper, Harvard University, 1994.

DeLong, J.B., and L. Summers. "Equipment Investment and Economic Growth." Quarterly Journal of Economics. May 1991, 106(2), pp. 455-502.

Gelb, A.H. Windfall Gains: Blessing or Curse?, New York: Oxford University Press, 1988.

Hirschman, A. O. The Strategy of Economic Development. New Haven CT: Yale University Press, 1958.

King, R.G. and R. Levine. "Finance and Growth: Schumpeter Might be Right." Quarterly Journal of Economics. August 1993, 108(3), pp. 717-737.

Knack, Stephen and Keefer, Philip (1995, forthcoming). "Institutions and Economic Performance: Empirical Tests using Alternative measures of Institutions." Economics and Politics (also IRIS Working Paper \#109).

Lane, P. and A. Tornell. "Power Concentration and Growth," Harvard Institute of Economic Research Discussion Paper No. 1720, May 1995.

Lewis, S.R. "Primary Exporting Countries." Chapter 29 in Hollis Chenery and T.N. Srinivasan, eds., Handbook of Development Economics, Volume II. Amsterdam: North-Holland, 1989, pp. 1541-1600.

Matsuyama, K. "Agricultural Productivity, Comparative Advantage, and Economic Growth." Journal of Economic Theory. 1992. 58, pp. 317-334.

Mauro, P. "Corruption and Growth." The Quartenly Journal of Economics, Volume CX, Issue 3, pp. 681712, August, 1995. 
Roemer, M. Fishing for Growth; Export-led Development in Peru, 1950-1967. Cambridge MA: Harvard University Press, 1970.

Sachs, J.D. and A.M. Warner. "Economic Convergence and Economic Policies", unpublished paper, Harvard University, January 1995.

Sachs, J.D. and A.M. Warner. "Economic Reform and the Process of Global Integration," Brookings Papers on Economic Activity, 1995:1, pp. 1-118.

Seers, D. "The Mechanism of an Open Petroleum Economy." Social and Economic Studies, 1964:13, pp. 233-242.

Taylor, A.M. "Domestic Saving and International Capital Flows Reconsidered", NBER Working Paper No. 4892, October, 1994.

Timmer, C.P. "Energy and Structural Change in the Asia-Pacific Region: The Agricultural Sector." Development Discussion Paper No. 140, Harvard Institute for International Development, October, 1982.

Warner, A.M. "Mexico's Investment Collapse: Debt or Oil?", Journal of International Money and Finance, Vol. 13, No. 2, pp. 240-256, April, 1994.

Young, A. "Learning by Doing and the Dynamic Effects of International Trade." Quarterly Journal of Economics, May 1991, vol. CVI, No. 2, pp. 369-406. 